Research Paper

\title{
Simulation of surface energy fluxes and meteorological variables using the Regional Atmospheric Modeling System (RAMS): Evaluating the impact of land-atmosphere coupling on short-term forecasts
}

\author{
I. Gómez ${ }^{\mathrm{a}, \mathrm{b}, *}$, V. Caselles ${ }^{\mathrm{a}}$, M.J. Estrela ${ }^{\mathrm{c}}$, J.M. Sánchez ${ }^{\mathrm{d}}$, E. Rubio ${ }^{\mathrm{e}}$ \\ ${ }^{a}$ Earth Physics and Thermodynamics Department, Faculty of Physics, University of Valencia, Doctor Moliner, 50, 46100 Burjassot, Valencia, Spain \\ b Environment and Earth Sciences Department, Faculty of Sciences, University of Alicante, Section 99, E-03080 Alicante, Spain \\ c Geography Department, Faculty of Geography and History, University of Valencia, Avda. Blasco Ibáñez, 28, 46010 Valencia, Spain \\ d Applied Physics Department, EPC and IDR, University of Castilla-La Mancha, Avda. España s/n, 02071 Albacete, Spain \\ e Applied Physics Department, University of Castilla-La Mancha, Avda. España s/n, 02071 Albacete, Spain
}

\section{A R T I C L E I N F O}

\section{Keywords:}

Mesoscale modelling

Land surface models

Soil initialization

Numerical weather prediction/forecasting

Land cover

Surface energy fluxes

\begin{abstract}
A B S T R A C T
Atmospheric mesoscale numerical models are commonly used not only for research and air quality studies, but also for other related applications, such as short-term weather forecasting for atmospheric, hydrological, agricultural and ecological modelling. A key element to produce faithful simulations is the proper representation of the soil parameters used in the initialization of the corresponding mesoscale numerical model. The Regional Atmospheric Modeling System (RAMS) is used in the current study. The model code has been updated in order to permit the model to be initialized using a heterogeneous soil moisture and temperature distribution derived from land surface models. Particularly, RAMS has been adapted to incorporate the Global Land Data Assimilation System (GLDAS) dataset for the initialization of the corresponding soil parameters. The results obtained using this heterogeneous initialization are compared to the model results obtained by the default homogeneous RAMS initializations. A series of numerical experiments have been conducted for a 7-days period over eastern Spain within the 2011 summer season. The selected period covers different typical summer atmospheric situations from the region of study. Ground data from two FLUXNET stations, together with the measurements registered by a portable weather station, located over the region of study, and other permanent weather stations are used for the result assessment. Incorporating the GLDAS product in the initialization of RAMS has been found to remarkably improve the representation of surface sensible weather parameters. On the other hand, significant differences are still observed in the proper simulation of the surface parameters when the model is applied to well vegetated areas in comparison to those obtained over poor and/or sparsely vegetated regions. Considering the better agreement found in this latter case, we have performed several sensitivity tests regarding land-surfaceatmosphere coupling with the aim of improving the original results over well vegetated areas.
\end{abstract}

\section{Introduction}

The Regional Atmospheric Modeling System (RAMS) is being used for research and weather forecasting purposes as well as for climate and air quality studies. This model has previously been applied operationally over the Western Mediterranean coast (see e.g. Gómez et al., 2014a,b,c, 2015a, 2016a). Assuming minor errors in the large scale flow in the boundary conditions, mesoscale meteorological models rely on the skill of the formulation for the Planetary Boundary Layer (PBL), the soil, and the land surface (Steeneveld et al., 2011). Related to the soil and land surface, it has been found that variations in its state have a significant effect on surface fluxes, the overlying atmosphere, and, ultimately, on local and regional climate, that are projected to strengthen under future climate change (Dirmeyer et al., 2013). In this regard, Soil Moisture (SM) plays a key role in the partitioning of net radiation between sensible and latent heat flux at the land surface to atmosphere (Dirmeyer et al., 2014; Gallego-Elvira et al., 2016). There is a clear connection between SM and surface fluxes and, in addition, surface fluxes affect the atmosphere through the impact on air temperature, humidity and the occurrence and intensity of precipitation. Following this argument, SM is then critical in the simulation of the atmospheric boundary layer, which is a first-order control on simulated pollutant (see e.g. Juang et al., 2007a,b; Angevine et al., 2014).

Considering all these interactions and feedbacks, different studies

\footnotetext{
* Corresponding author at: Earth Physics and Thermodynamics Department, Faculty of Physics, University of Valencia, Doctor Moliner, 50, 46100 Burjassot, Valencia, Spain.

E-mail address: Igor.Gomez@uv.es (I. Gómez).
} 
have been performed with the aim of examining and studying the land and atmosphere conditions and interactions (see e.g. De Goncalves et al., 2006; Koster et al., 2009; Betts, 2009; Seneviratne et al., 2010; Dirmeyer et al., 2012; Dirmeyer et al., 2013; Ferguson et al., 2012; Santanello et al., 2013; Zaitchik et al., 2013; Meng and Shen, 2014; Pathirana et al., 2014; Hirsch et al., 2014; Daniels et al., 2015; Dirmeyer and Halder, 2016). All these studies have highlighted the significant importance of soil parameters, specially focused on the relationship between the SM field and sensible weather parameters. Additionally, the spatial distributions of SM are affected by the land surface hydrological processes (e.g. precipitation, ET or runoff processes) as well as by the heterogeneity of topography, soil properties, and land cover characteristics (Lin and Cheng, 2016).

In relation to NWP models, a special challenge not faced by operational systems is the proper initialization of SM. In this regard, the central role of SM in mesoscale modelling has recently been emphasized (see e.g. Angevine et al., 2014; Daniels et al., 2015; Gómez et al., 2015b; Dillon et al., 2016; Gómez et al., 2016b; Kalverla et al., 2016). All these studies have shown that an appropriate initialization of the SM conditions would have a positive impact on short-term forecasts. Another soil parameter that has been found to be of meaningful significance is the Soil Temperature (ST). The role of ST in mesoscale modelling has also been evaluated by Gómez et al. (2016c) for extreme heat events. Contrasting SM with ST, it has been found that SM presents a more marked effect during the day, while ST shows a more marked impact at night (Gómez et al., 2015b, 2016b,c).

In general, it is difficult to attain a correct representation of the soil parameters. Most of the data is obtained during field campaigns which are regional and sporadic, so it cannot be used to initialize NWP models (Dillon et al., 2016). An alternative to these limitations has been to use satellite estimations, such as SMOS (Soil Moisture and Ocean Salinity) and SMAP (Soil Moisture Active Passive) sensors, in order to have a wide spatial and temporal coverage (see e.g. Entekhabi et al., 2010; Kerr et al., 2010; Leroux et al., 2016; Burgin et al., 2017). Those estimations generally correspond to the superficial SM from a layer of a few centimetres depth. Therefore, the initial SM and ST fields for NWP models are usually prescribed based on homogeneous initializations or provided from analysis and/or reanalysis fields. Currently, there are many uncoupled Land Surface Model (LSM), such as the Global Land Data Assimilation System (GLDAS; Rodell et al., 2004) that can also be used in this regard. GLDAS is a methodology that generates products derived from different four uncoupled LSMs: the Community Land Model (CLM), Mosaic, Noah and Variable Infiltration Capacity (VIC), forced with observations and uncoupled from an atmospheric model. Monthly and three hourly fields are available from distinct depths for all these models at $1 \times 1$ horizontal degree resolution globally (Lin and Cheng, 2016; Dillon et al., 2016). In addition, the Noah LSM is also provided by GLDAS version 1 at a $0.25 \times 0.25$ horizontal degree resolution and with a 3-hourly temporal resolution. In the current study, the dataset produced by this version of the Noah LSM is incorporated into the RAMS initialization environment in order to provide an alternative to its default homogeneous initialization. GLDAS Noah LSM is based on 4 soil layers $(0-0.1,0.1-0.4,0.4-1.0,1.0-2.0 \mathrm{~m})$ with a horizontal spatial resolution of $0.25 \times 0.25^{\circ}$ globally.

The current study performs a comprehensive evaluation of the RAMS model over eastern Spain, including variables not usually available, such as the surface turbulent fluxes. In addition, with the aim of obtaining a deeper insight of the influence of the initial soil parameters on the modelling results, and bearing in mind the improvement of short to medium range weather forecasting of near surface variables, we investigate the effect and impact of soil initializations on standard and non-standard surface and near-surface atmospheric fields. In this sense, we start from the homogeneous RAMS initialization which, as we will see in the current study, imposes a significant limitation in the adequate representation of the actual soil conditions, then we implement a heterogeneous initialization based on the GLDAS Noah LSM product. We would like to answer the following questions: (1) what is the impact of the soil initial conditions in the short-term forecasts produced by the model, (2) is it possible to improve the model performance using the GLDAS Noah LSM database at $0.25 \times 0.25$ horizontal degree resolution in its initialization, (3) what are the strengths and weaknesses of the representation of key physical processes when using this soil initial condition and (4) what is the model performance over different regions within the area of study according to in-situ conditions.

The paper is organised as follows. Section 2 introduces the study area and the available observations. A detailed description of the experimental design and the modelling strategy is provided in Section 3, while the simulation results are presented in Section 4. Finally, conclusions are drawn in Section 5.

\section{Observational datasets and study area}

Data from three meteorological stations are used in the current work to validate and compare the observations with the RAMS results. Two of these three stations are tower FLUXNET sites and use eddy covariance methods to measure $\mathrm{CO}_{2}$, water vapour, and energy fluxes between the terrestrial ecosystem and the atmosphere. One of the towers, (ALM site), is located $1 \mathrm{~km}$ apart from Almodóvar del Pinar, in the mountain range of Cuenca (central-eastern Spain) in a forest called "Dehesa de Abajo" (1000 m .a.s.l., $39^{\circ} 40^{\prime} \mathrm{N}, 1^{\circ} 55^{\prime} \mathrm{W}$ ), whereas the second tower is located in El Bonillo (BON site) juniper woodlands (956 m a.s.1., 38 $56^{\prime} \mathrm{N}, 2^{\circ} 38^{\prime} \mathrm{W}$ ). The third station, (BRX site), is a permanent weather station located in "Las Tiesas" experimental farm $\left(2^{\circ} 5^{\prime} \mathrm{W}, 39^{\circ} 14^{\prime} \mathrm{N}\right.$, $695 \mathrm{~m}$ a.s.l) close to Albacete (central Spain) (see Fig. 1). According to the Koppen-Geiger Climate Classification (Peel et al., 2007), the climate in these areas is cold semi-arid (type Bsk). The ALM study area is dominated by a natural uneven-aged mixed forest. This forest encompasses an area of approximately 4430 ha, and has a rather homogeneous structure and composition. It is consisting mainly of a dominant canopy tree layer of Pinus pinaster Ait. subsp. mesogeensis (Mediterranean Maritime pine), average age of 70 years, with a subdominant tree layer of Quercus ilex L. subsp. Ballota (Holm oak). Shrub species composition includes Rosmarinus officinalis L., Thymus vulgaris L., Lavandula latifolia L. Quercus coccifera, and Genista scorpius L. This forest is considered a mountain plain, where slopes do not exceed a $3 \%$ gradient. Mean annual temperature and precipitation are $15.5{ }^{\circ} \mathrm{C}$ and $510 \mathrm{~mm}$. The dominant soil in the stand is Lithic Leptosol, associated with Chromic Luvisol, a very shallow soil over calcareous hard rock (FAO, 1988). Soil analysis revealed a sandy loam texture with $60 \%$ sand, $16 \%$ silt and $24 \%$ clay (López-Serrano et al., 2015; López-Serrano et al., 2016).

The BON study area represents one of the main semi-arid Spanish juniper distributions, covering 12,872 ha. In this area, J. thurifera forms pure stands growing on the more adverse soils while it is also found associated with Quercus ilex in the best soils. The eddy covariance tower is located in a mature woodland, characterized by a low density of juniper trees (over 150 years old), that grow in shallow stony soils. Dominant soil type is Lithic leptosol (FAO, 1988) with a mean effective soil depth lower than $15 \mathrm{~cm}$. Long-term (30-year average) mean annual and growing season temperatures at the site are 12.8 and $17.9^{\circ} \mathrm{C}$ respectively, and mean annual and growing season precipitation are 452 and $234 \mathrm{~mm}$ respectively. Temperature extremes range from 43 to $-21^{\circ} \mathrm{C}$ (data from El Bonillo climatic station: $38^{\circ} 57^{\prime} \mathrm{N}, 01^{\circ}$ 09’ W; $1068 \mathrm{~m}$.a.s.l.) (García Morote et al., 2012).

The BRX site is a flat agricultural area with a variety of croplands. The soil is classified as Petrocalcic Calcixerepts, with a silty-clayloam texture $(13.4 \%$ sand, $48.9 \%$ silt and $37.7 \%$ clay). For a detailed description of this site and of the automatic weather station placed in the area, see Sánchez et al. (2011) and López-Urrea et al. (2006). In the summer of 2011 sunflower was sowed in one of the fields close to the weather station, and surface energy fluxes were estimated during the 


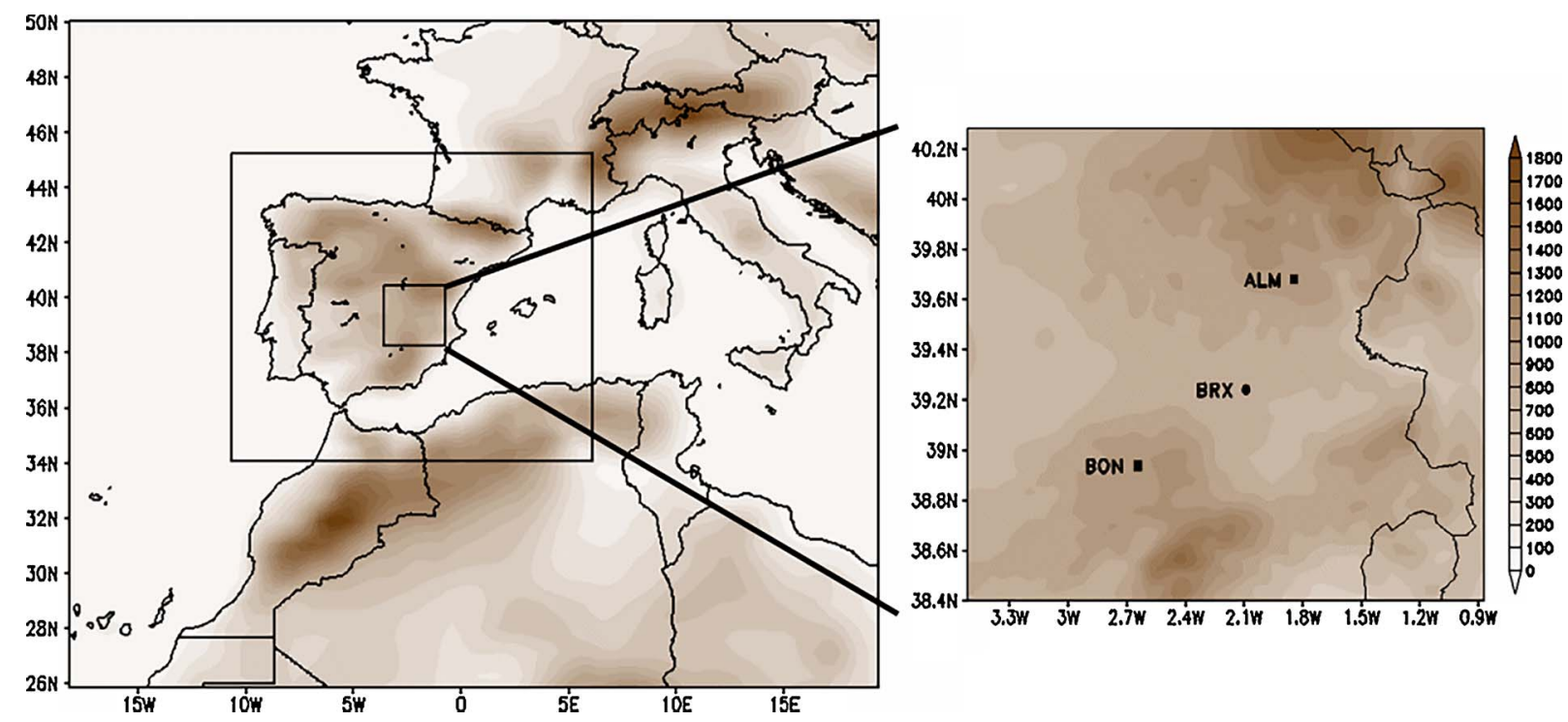

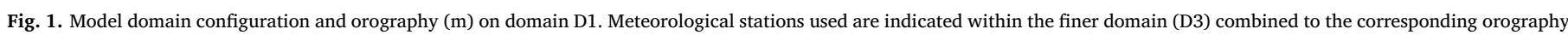
(m).

full campaign. During the experiment crops were irrigated using a sprinkling system, avoiding water stress conditions at any time.

In terms of physical magnitudes available for the validation process, hourly measures of 2-m temperature and relative humidity, and 10-m wind speed and direction are used, while the observed wind speed and direction at $18-\mathrm{m}$ is instead applied over ALM. Moreover, the observational datasets of both ALM and BON include other variables not usually available, such as the surface turbulent fluxes, and the SM content in the case of ALM. These additional variables are also used in the current evaluation and could help to perform a profound analysis and evaluate whether there is any deficiency in the simulation of the fluxes behind (Steeneveld et al., 2011).

On the other hand, a simplified version of the two-source configuration (STSEB) (Sánchez et al., 2008) was used to estimate the surface energy fluxes in the BRX site. This version uses direct radiometric temperature measurements as the main input, and includes a simple approach to predict the net radiation partitioning between soil and vegetation. Feasibility of STSEB to obtain accurate surface energy fluxes has been already assessed in a variety of croplands (Sánchez et al., 2008, 2011, 2014, 2015a,b), and natural vegetation (Sánchez et al., 2009, 2015a,b).

\section{Modelling strategy and methodology}

The selected forecasting period has been simulated based on the RAMS model (Cotton et al., 2003; Pielke, 2013), version 6.0, using three nested domains with horizontal resolution of $48 \mathrm{~km}, 12 \mathrm{~km}$ and $3 \mathrm{~km}$, respectively, while a total of 45 levels were selected in the vertical. In the current configuration, 22 levels are included in the lowest $2000 \mathrm{~m}$ while 8 levels are present in the lowest $300 \mathrm{~m}$.

Regarding physical parameterizations, RAMS uses the YSU PBL scheme (Hong et al., 2006; Gómez et al., 2016b). This PBL parameterization is coupled to the Land-Ecosystem Atmosphere Feedback Model (LEAF-3; Walko et al., 2000). In addition, the physical parameterization schemes include the Chen-Cotton scheme for longwave and shortwave radiation (Chen and Cotton, 1983). On the other hand, the Kain-Fritsch scheme for convection is used (Castro et al., 2002) on the two most outer grids. LEAF represents the surface energy budget, which partitions the net radiation into sensible, latent (evaporation plus transpiration), and soil heat fluxes. It incorporates the interactions between soil and vegetation, and their influence on each other and on the atmosphere at a subgrid scale (Walko et al., 2000). In this regard, the evapotranspiration rate from vegetation to canopy air is computed by LEAF-3 following the next expression (Pielke, 2013):

$E=\rho\left(q_{v s}-q_{c}\right)\left[\frac{\left(\frac{W_{f}}{W_{m}}\right)^{2 / 3}}{r_{b}}+\frac{1-\left(\frac{W_{f}}{W_{m}}\right)^{2 / 3}}{r_{b}+r_{c}}\right]$

where $\rho$ is the air density $\left(\mathrm{kg} \mathrm{m}^{-3}\right), \mathrm{q}_{\mathrm{vs}}$ and $\mathrm{q}_{\mathrm{c}}$ are the saturated specific humidity at vegetation temperature $\left(\mathrm{kg} \mathrm{kg}^{-1}\right)$ and the specific humidity of the canopy air $\left(\mathrm{kg} \mathrm{kg}^{-1}\right)$, respectively, $\mathrm{W}_{\mathrm{f}}$ and $\mathrm{W}_{\mathrm{m}}$ are the water stored by vegetation $\left(\mathrm{kg} \mathrm{m}^{-2}\right)$ and the maximum water reservoir capacity $\left(\mathrm{kg} \mathrm{m}^{-2}\right)$, respectively, $\mathrm{r}_{\mathrm{b}}$ is the bulk leaf boundary-layer resistance $\left(\mathrm{s} \mathrm{m}^{-1}\right)$, and $r_{c}$ is the canopy resistance $\left(\mathrm{s} \mathrm{m}^{-1}\right)$. Canopy air in vegetated areas is defined as air in close proximity to and influenced by vegetation (Walko et al., 2000). LEAF-3 computes the temperature of canopy air considering the surface sensible heat fluxes from ground to canopy and from vegetation to canopy, and including a term proportional to the frictional temperature as well. Actually, Eq. (1) accounts from the evaporation rate (first component in the square bracket term) and the transpiration rate (second element in the square brackets term). Evaporation is then related to the bulk leaf boundary-layer resistance, defined based on the following equation:

$r_{b}=\frac{P_{S}}{C_{f} L S A I}\left(\frac{l}{U_{f}}\right)^{1 / 2} ; P_{s}=1+0.5 L S A I$

where $P_{s}$ represents the shelter factor, $C_{f}$ is a constant value of $0.01 \mathrm{~m} \mathrm{~s}^{-1 / 2}$, LSAI is the leaf and stem area index, 1 accounts for the topical dimension of leaves or the stems along the wind directions (m), and $U_{\mathrm{f}}$ is the magnitude of wind within the canopy $\left(\mathrm{m} \mathrm{s}^{-1}\right)$.

The transpiration term in Eq. (1) accounts for the water than can be extracted from the root zone of the plant, and is related to the bulk leaf boundary-layer resistance as well as to the canopy resistance, where the latter is defined using the next expression, and measures the biological resistance of a canopy to losses of water (Pielke, 2013):

$r_{c}=\frac{1}{L A I}\left[d_{s \min } f_{R} f_{T c} f_{T h} f_{v} f_{\psi}\right]^{-1}$

where LAI is the leaf area index, $d_{s m i n}$ represents for the minimum stomatal conductance $\left(\mathrm{m} \mathrm{s}^{-1}\right)$, and $\mathrm{f}_{\mathrm{R}}, \mathrm{f}_{\mathrm{Tc}}, \mathrm{f}_{\mathrm{Th}}, \mathrm{f}_{\mathrm{v}}$ and $\mathrm{f}_{\psi}$ are five adjustment factors accounting for the total solar radiation, leaf temperature at cold range, leaf temperature at hot range, water vapour pressure deficit and soil water potential, respectively. Any moisture that 
transpires from the vegetation must be taking from the soil, as indicated below. Transpiration is then limited by stomatal resistance and soil dryness.

Considering the transfer of water between soil layers, the moisture flux between these layers is based on a multilayer soil as described by Mahrer and Pielke (1977) and McCumber and Pielke (1981), but following the modifications applied by Tremback and Kessler (1985), where the different iteration processes were removed. In this scheme, the hydraulic and thermal diffusion properties of the soil are considered by incorporating the SM diffusion equation into the LEAF model. Particularly, the equation used to calculate the moisture flux $\left(\mathrm{W}_{\mathrm{s}}\right)$ is given by:

$W_{s}=-\rho_{w} K_{\eta} \frac{\partial(\psi+z)}{\partial z}$

where $\rho_{\mathrm{w}}$ is the density of liquid water $\left(\mathrm{kg} \mathrm{m}^{-3}\right), \mathrm{K}_{\eta}$ is the hydraulic conductivity $\left(\mathrm{m} \mathrm{s}^{-1}\right), \psi$ corresponds to the matric potential $(\mathrm{m})$ needed to calculate the moisture diffusivity in the root zone, and representing the work required to extract water from the soil against capillary and adhesive forces, and $\mathrm{z}$ is a vertical coordinate within the soil profile $(\mathrm{m})$, defined positive upwards. The parameterization of the hydraulic properties adopted in LEAF-3 is that proposed by Clapp and Hornberger (1978), where $K_{\eta}$ and $\psi$ are calculated from the following empirical power curves:

$\psi=\psi_{s}\left(\frac{\eta_{s}}{\eta}\right)^{b}$

$K_{\eta}=K_{\eta s}\left(\frac{\eta}{\eta_{s}}\right)^{2 b+3}$

where $\eta$ is the actual volumetric SM content and $\eta_{\mathrm{s}}$ is the saturation volumetric $\mathrm{SM}$ content, $\mathrm{K}_{\mathrm{\eta}}$ is the saturation soil hydraulic conductivity, which is taken constant with depth, and $\mathrm{b}$ an experimental constant tabulated for each soil type. On the other hand, $\psi_{\mathrm{s}}$ is the matric potential where the SM content begins to be lower than the saturation water content in the $\psi(\eta)$ curve. A more detailed description of the hydraulic scheme can be found in Avissar and Pielke (1989).

The SM diffusion equation takes into account as well the soil water extraction by roots caused by plant transpiration. This is proportional to the root distribution and the soil water potential. In this regard, the root level for the RAMS configuration is calculated depending on the dominant vegetation over the corresponding location. Currently, the method implemented in LEAF-3 for root profile and water extractibility is based on first finding the bottom soil level in the root zone for the corresponding vegetation type, and then using this soil level to remove water only from the moistest level in the root zone for transpiration. In this regard, the greater the transpiration, the greater the water loss and lower soil moisture is available to be released into the atmosphere as latent heat flux.

RAMS is applied to simulate the period from 6 to 12 July 2011. For each of these days, this model has been used in reforecast mode, performing a daily simulation with a forecast horizon of $36 \mathrm{~h}$ and a temporal resolution of $1 \mathrm{~h}$, starting at 12 UTC the previous day. Thus, the first $12 \mathrm{~h}$ are left out as a spin-up period, and only the corresponding complete day (the remaining $24 \mathrm{~h}$ ) is considered in the evaluation. Hence, this method reduces the uncertainties, keeping the model close to the forcing fields but still free enough to generate mesoscale features. The NCEP FNL (NCEP, 2015) dataset at $6 \mathrm{~h}$ intervals and $1 \times 1^{\circ}$ resolution globally were used as initial and boundary conditions for RAMS.

We have designed a set of sensitivity experiments (Table 1 ) in order to evaluate the influence of soil parameters in the short-term forecasts using RAMS. In this regard, a total of seven runs have been performed for each individual day within the period of study. The reference run considering all sensitivity tests is that provided by RAMS using a homogeneous initialization that applies a constant volumetric SM value of $0.10 \mathrm{~m}^{3} \mathrm{~m}^{-3}$ (Ref) for all soil levels and all land grid points within the simulation domain. Another homogeneous initialization has been carried out but doubling the original homogeneous SM value to $0.20 \mathrm{~m}^{3} \mathrm{~m}^{-3}$ (simulation SM_020). The choice of these two apart SM values is based on the results previously found by Gómez et al. (2015b) over the Western Mediterranean coast. A third RAMS run (SM_GLDAS) applies the SM provided by the GLDAS version 1 Noah uncoupled LSM. In this case, a new routine code has been developed, thus allowing a heterogeneous initialization within the RAMS modelling environment. This is performed by means of the LEAF sub-model. Considering not only the GLDAS SM but also the ST, another RAMS simulation is performed incorporating both soil parameters (SOIL_GLDAS). In all these RAMS runs, a total of 11 soil levels are used with higher resolution on the uppermost layers down to a depth $50 \mathrm{~cm}$ below the surface for the soil model. However, an additional simulation has been performed including two additional soil levels, covering the depths of 100 and $150 \mathrm{~cm}$, respectively, thus providing a total of 13 soil levels. Applying this soil layer structure, a new RAMS simulation has been conducted in order to evaluate the soil depth in the model results while still maintaining a finer soil profile structure in the uppermost soil model, using the GLDAS soil parameters in the RAMS initialization (SOIL_GLDAS_L2). In order to input the GLDAS SM and ST into the RAMS three nested model domains, GLDAS is regridded considering the "nearest point" method (Gómez et al., 2016c). The outcome data is then mapped to the RAMS grid point within the corresponding simulation domain. Additionally, each soil level used in the RAMS configuration is informed with data derived from the corresponding 4 soil layer (0-0.1, 0.1-0.4, $0.4-1.0,1.0-2.0 \mathrm{~m}$ ) available in the GLDAS framework.

Based on the results founds (included in the next section), a new set of RAMS experiments have been performed applying the 13 soil levels (L2) configuration with the aim of evaluating the soil water loss used for transpiration within the LEAF-3 model. In this case, we have redefined the LEAF code in charge of computing this magnitude by means of two distinct updates. Firstly, we increase the simulated transpiration (TRANSP_MOD), by manually doubling this magnitude in the LEAF code, leading to a greater removal of the soil water loss. Secondly, we use the soil capacity as the maximum limit that can be removed from the available SM when computing the soil water loss (SOILC).

Results derived from the different RAMS simulations are compared to the observations considering the inner simulation domain (Fig. 1), with horizontal grid resolution of $3 \mathrm{~km}$. In order to quantify the model errors, three statistical indices and measures of error have been computed. This statistical analysis includes the mean bias, the centered root mean square difference (RMS) and the index of agreement (IoA), which is a modified correlation coefficient that measures the degree to which a model's prediction is free of error. A value of 0 means complete disagreement while a value of 1 implies a perfect agreement. The IoA is calculated following the next expression:

$$
I o A=1-\frac{\sum_{i=1}^{N}\left(F_{i}-O_{i}\right)^{2}}{\sum_{i=1}^{N}\left(\left|F_{i}-\bar{O}\right|+\left|O_{i}-\bar{O}\right|\right)^{2}}
$$

where $\mathrm{F}$ and $\mathrm{O}$ are the simulated and the observed values, respectively, $\mathrm{N}$ is the number of observations used to compute this statistical score, and $\mathrm{O}$ is the time averaged observation.

In order to perform the corresponding analysis, we have divided the whole simulation period (6-12 July 2011) according to the dominant atmospheric condition within each specific day. In this regard, a Western synoptic advection is well established over the area of study on 6, 7 and 8 July, while mesoscale circulations are developed on 9 and 10 July. In contrast, an Eastern synoptic advection is set over this region on 11 July. Finally, although a Western synoptic advection is once again established on 12 July, some cloudiness appears over some locations 
Table 1

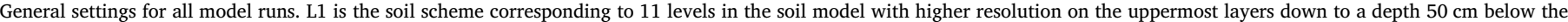

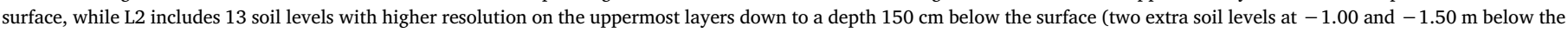
surface).

\begin{tabular}{|c|c|c|c|c|c|}
\hline Experiments & Meteorological Input Data & $\mathrm{SM}(\mathrm{D} 1, \mathrm{D} 2, \mathrm{D} 3)\left(\mathrm{m}^{3} \mathrm{~m}^{-3}\right)$ & ST (D1, D2, D3) (K) & Soil Level Scheme & RAMS modification \\
\hline REF & FNL & 0.10 & - & L1 & - \\
\hline SM_020 & FNL & 0.20 & - & L1 & - \\
\hline SM_GLDAS & FNL & GLDAS & - & L1 & - \\
\hline SOIL_GLDAS & FNL & GLDAS & GLDAS & L1 & - \\
\hline SOIL_GLDAS_L2 & FNL & GLDAS & GLDAS & $\mathrm{L} 2$ & - \\
\hline TRANSP_MOD & FNL & GLDAS & GLDAS & $\mathrm{L} 2$ & Transpiration to compute moisture removal \\
\hline SOILC & FNL & GLDAS & GLDAS & $\mathrm{L} 2$ & Soil Capacity to compute moisture removal \\
\hline
\end{tabular}
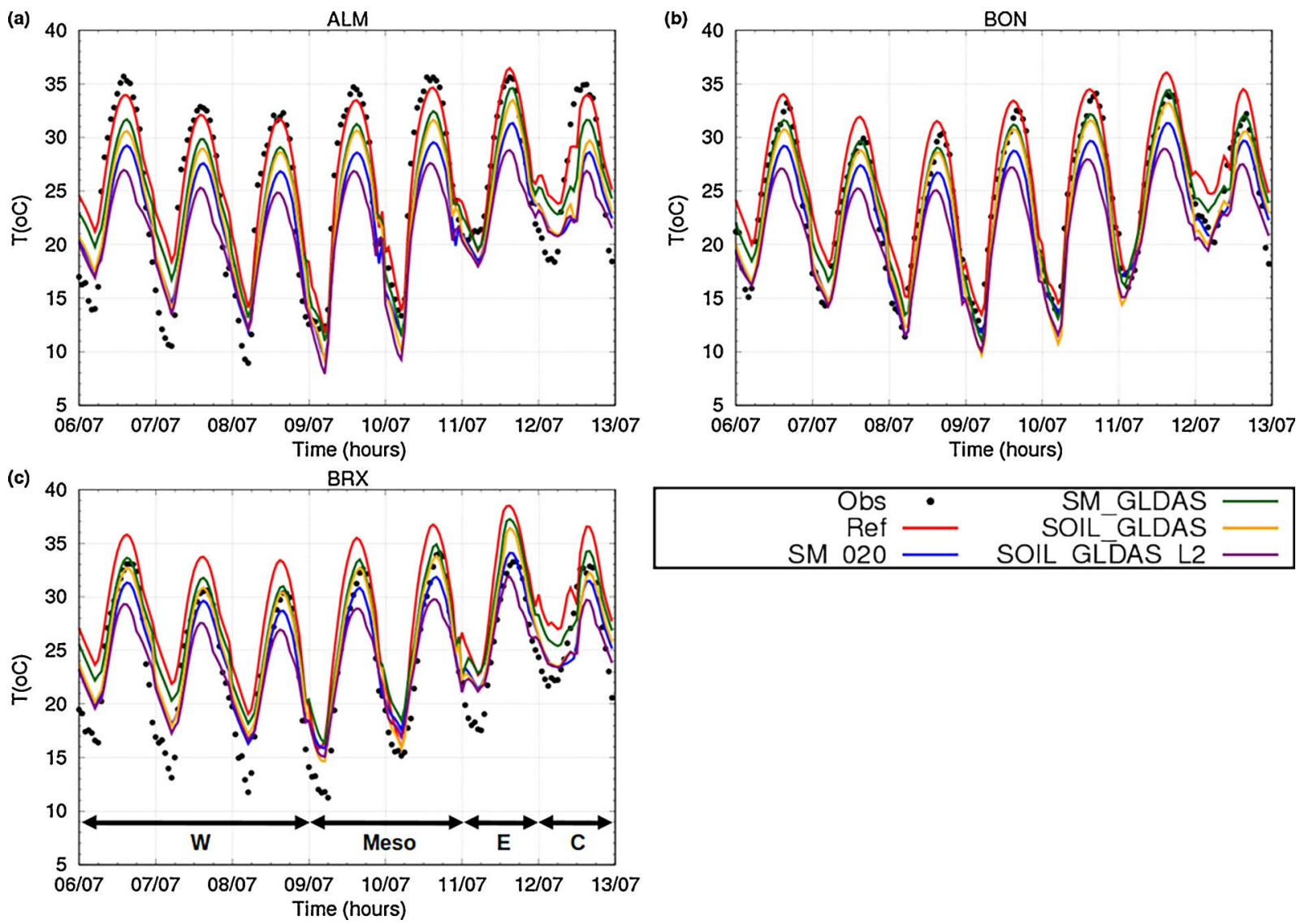

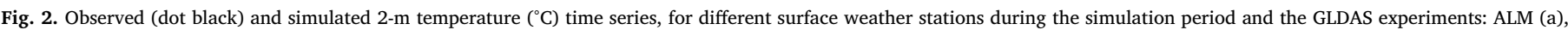

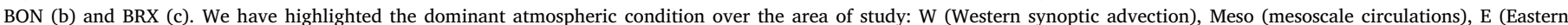
synoptic advection) and C (Western synoptic advection with the presence of cloudiness).

within the study area (see next section). Therefore, the corresponding atmospheric condition is considered in the analysis separately for the 6-12 July 2011 complete period.

\section{Results and discussion}

In order to discuss the results presented in the previous sections, we must consider two significant issues: on the one hand, the land use over the different measurement locations and, on the other hand, the irrigation conditions on these targets. These two points could help to clarify the results found.

In this section we answer the first three questions introduced at the end of the introduction section: (1) what is the impact of the soil initial conditions in the short-term forecasts produced by RAMS, (2) is it possible to improve the model performance using the GLDAS Noah LSM database at $0.25 \times 0.25$ horizontal degree resolution in its initialization, and (3) what are the strengths and weaknesses of the representation of key physical processes when using these soil initial conditions.

\subsection{What is the role of soil initial conditions in the short-term forecasts?}

RAMS simulations performed using different soil initial conditions are compared with available observations in the current and the next sections, considering the whole simulation period and three weather stations: ALM, BON and BRX. In order to clarify the analysis of the model results, we introduce at this point a summary of the different figures presented. First, the 2-m temperature is displayed in Fig. 2. Fig. 3 shows the sensible and latent heat fluxes over these locations. On the other hand, the wind field is presented in Figs. 4 and 5 over ALM and BON, respectively, while Fig. 6 shows the observed and simulated relative humidity over the three weather stations. Fig. 7 presents the 2$\mathrm{m}$ temperature and the surface turbulent fluxes over ALM and BON, considering all data simulated by Ref, SM_020 and SOIL_GLDAS runs. 

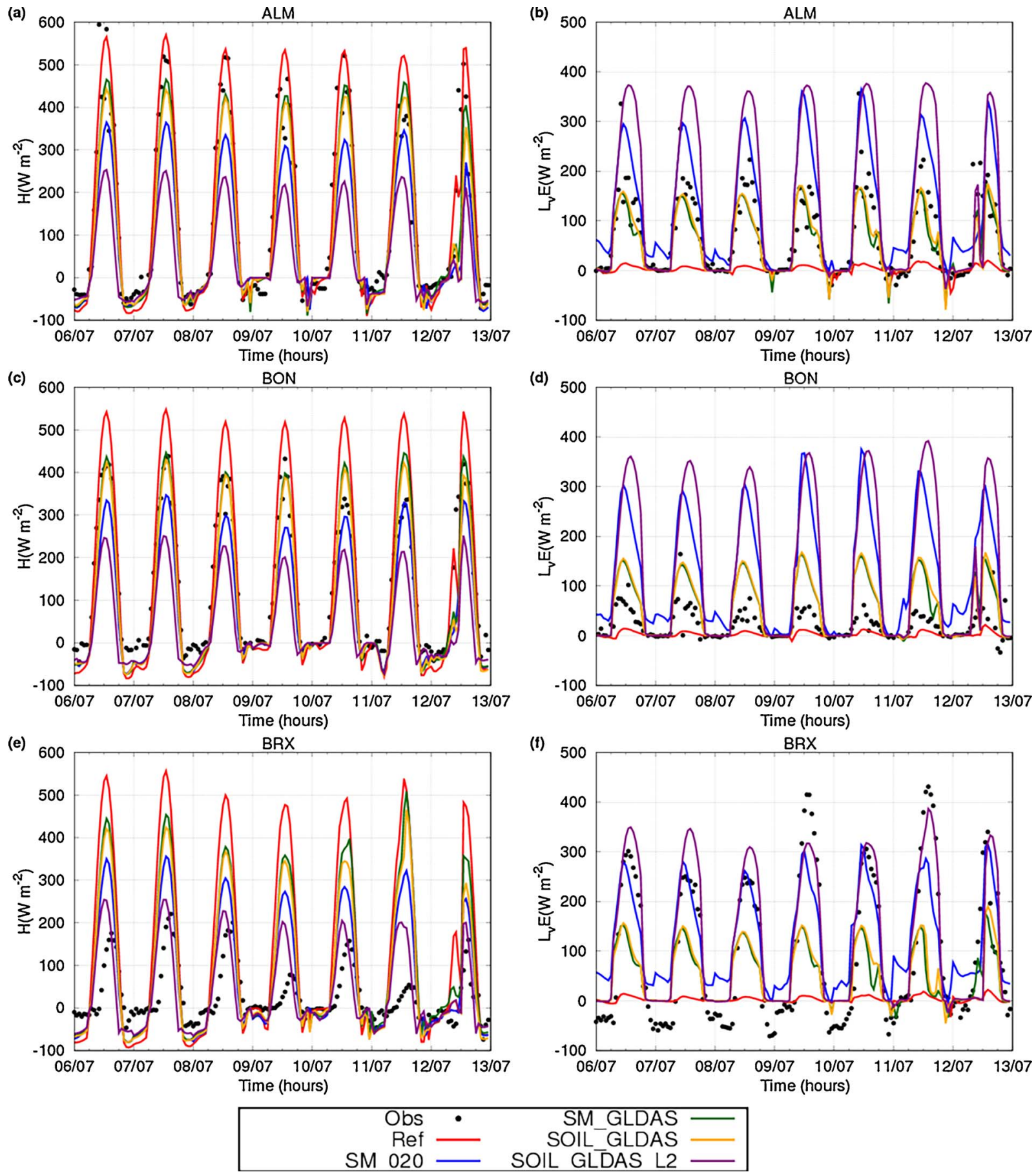

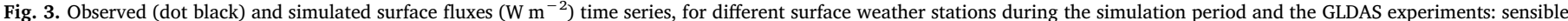
heat flux (left), ALM (a), BON (c), BRX (e), and latent heat flux (right): ALM (b), BON (d), BRX (f).

Finally, Fig. 8 is devoted to the simulation of the SM content.

By default, RAMS is initialized using an homogeneous distribution defined by the user in the model configuration. In the current study, RAMS code has been updated to permit the model to be initialized based on an heterogeneous land parameter distribution. Considering the model over BON, Ref produces a warm bias in the 2-m temperature (Fig. 2b). This result agrees with that previously found over the Western Mediterranean coast, using the Ref configuration (Gómez et al., 2015a,b, 2016b). Considering the surface fluxes simulated by Ref, it seems clear that this 2-m temperature warm bias is linked to an overestimation of the sensible heat flux (Fig. 3c), but with lower latent heat flux (Fig. 3d). However, SM_020 and SOIL_GLDAS_L2 produce a remarkable 2-m temperature cold bias which is directly related to an underestimation of the sensible heat flux and an overestimation of the latent heat flux. SOIL_GLDAS_L2 includes a large moisture content deeper underground. Fig. 3 shows that this additional moisture content is transported upwards, producing an increased latent heat flux by the release of soil moisture to the surface. The partitioning of the available surface energy between latent and sensible heat fluxes results in a decreased sensible heat flux, as shown in Fig. 3a, c and e. SM_GLDAS and SOIL_GLDAS captures the daytime 2-m temperature properly, but there appears a slight overestimation of the latent heat flux, which seems to produce a slight underestimation on the temperature field, while the sensible heat flux is simulated rather accurately (Fig. 3). These results 

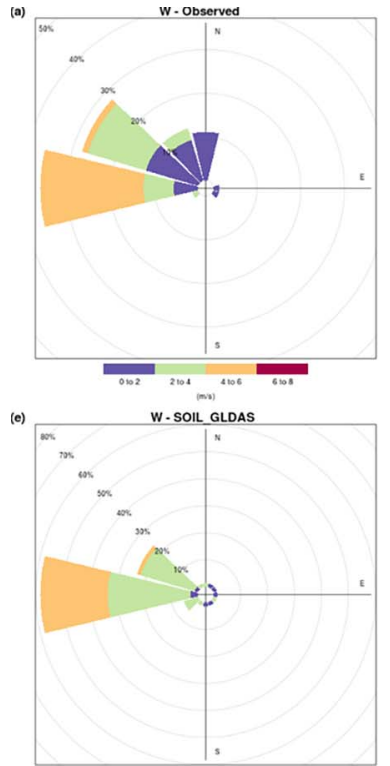
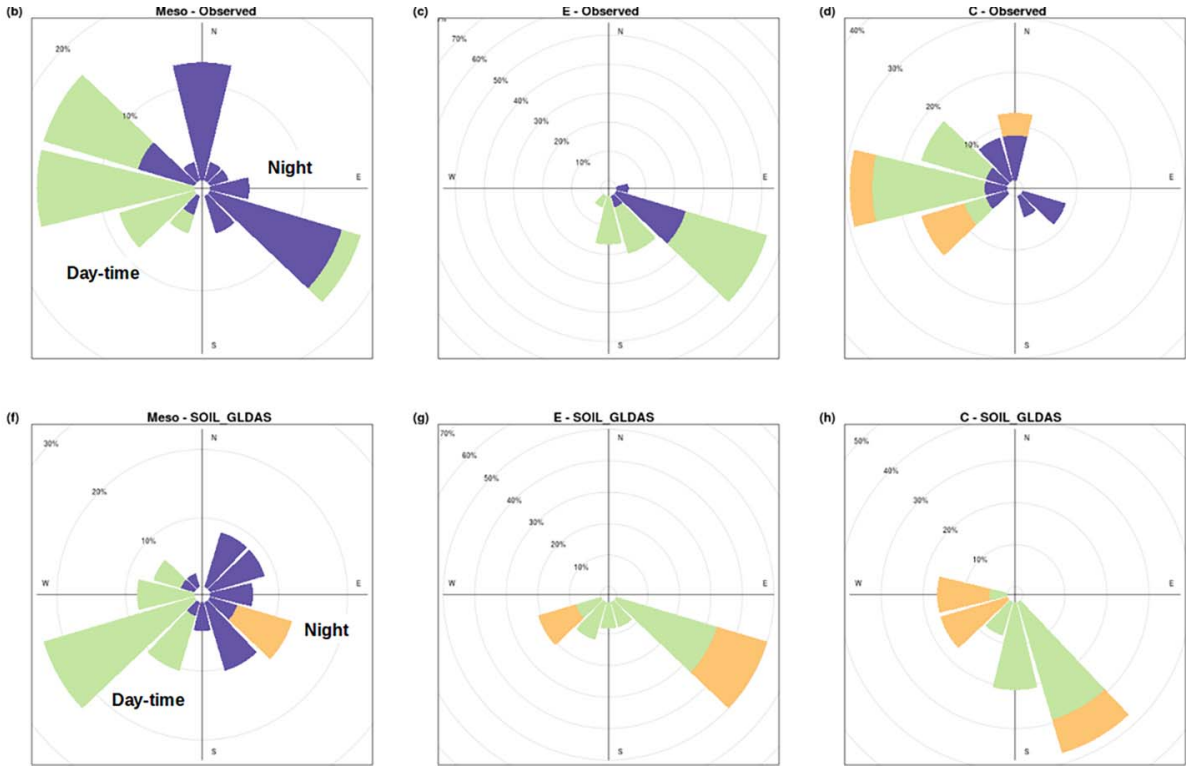

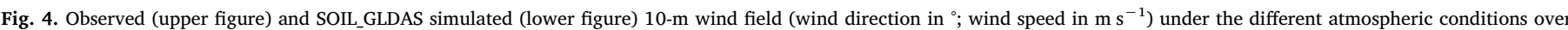

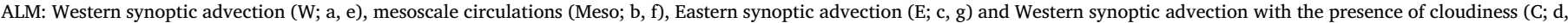
h).
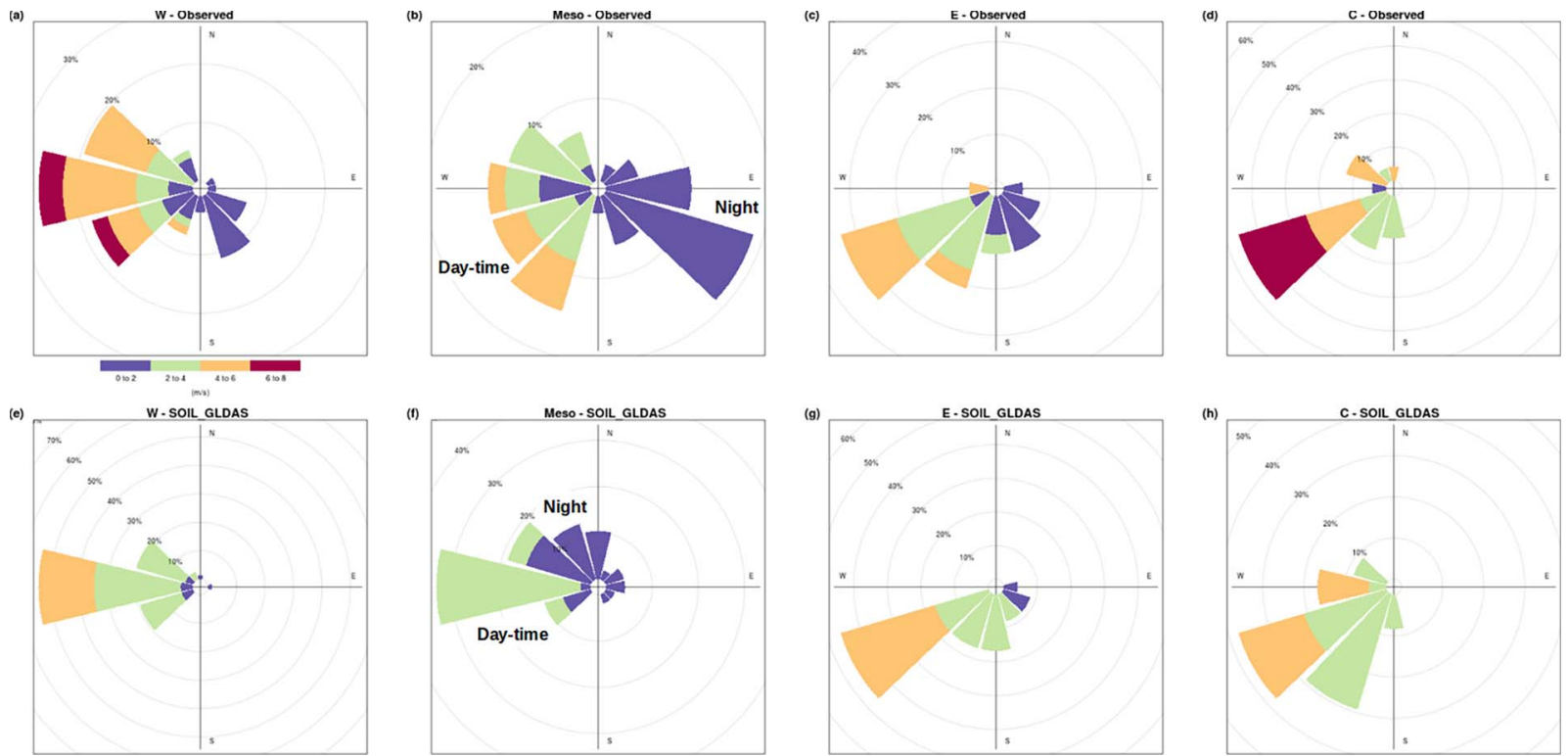

Fig. 5. Same as Fig. 4, but over BON weather station.

reflect a direct connection between the 2-m temperature biases and the surface fluxes. The results obtained over BON are representative of the study area and thus, it is expected that they could be transferred as the dominant summer conditions over the region, as it is also reflected by the 2-m temperature biases obtained for other weather stations over the study area (not shown). However, these stations do not measure the corresponding surface fluxes and we are not able to perform the same analysis as that presented for BON station (Fig. 3c and d). In general, SM_GLDAS shows similar results than SOIL_GLDAS for the daily temperatures, specially under mesoscale circulations, with more differences under western synoptic conditions. However, incorporating GLDAS ST data decreases the night-time temperature in comparison to the values simulated when only the GLDAS SM is included in the simulation. This reduction in the temperature difference between the observations and the simulations at night-time still maintains a significant gap under a western synoptic situation, but the minimum temperature is reliably simulated by RAMS using SM_GLDAS and specially when the
SOIL_GLDAS configuration is applied. Therefore, using the GLDAS soil parameters to initialize RAMS produces a really skilful representation of the 2-m temperature daily evolution, in particular during the daytime, thus reproducing the maximum temperature really well (Fig. 2).

Considering the results found in the current study, it is clear that incorporating the heterogeneous GLDAS soil parameters into RAMS produces a rather accurate representation of the temperature field, significantly improving the original homogeneous RAMS initializations. A proper representation of the soil parameters in the initial conditions applied to RAMS has been shown to be a way of reducing the bias between the model and the measurements. In general, soils are dry over the study area, specially during the summer season. It is not surprising that moistening the soil, such as in the SM_020 simulation, produces an underestimation of the simulated 2-m temperature. Therefore, it is of significant importance to introduce low SM values in the upper soil levels while high SM values are applied deeper underground, as using the GLDAS product (SM_GLDAS and SOIL_GLDAS). In this case, the 

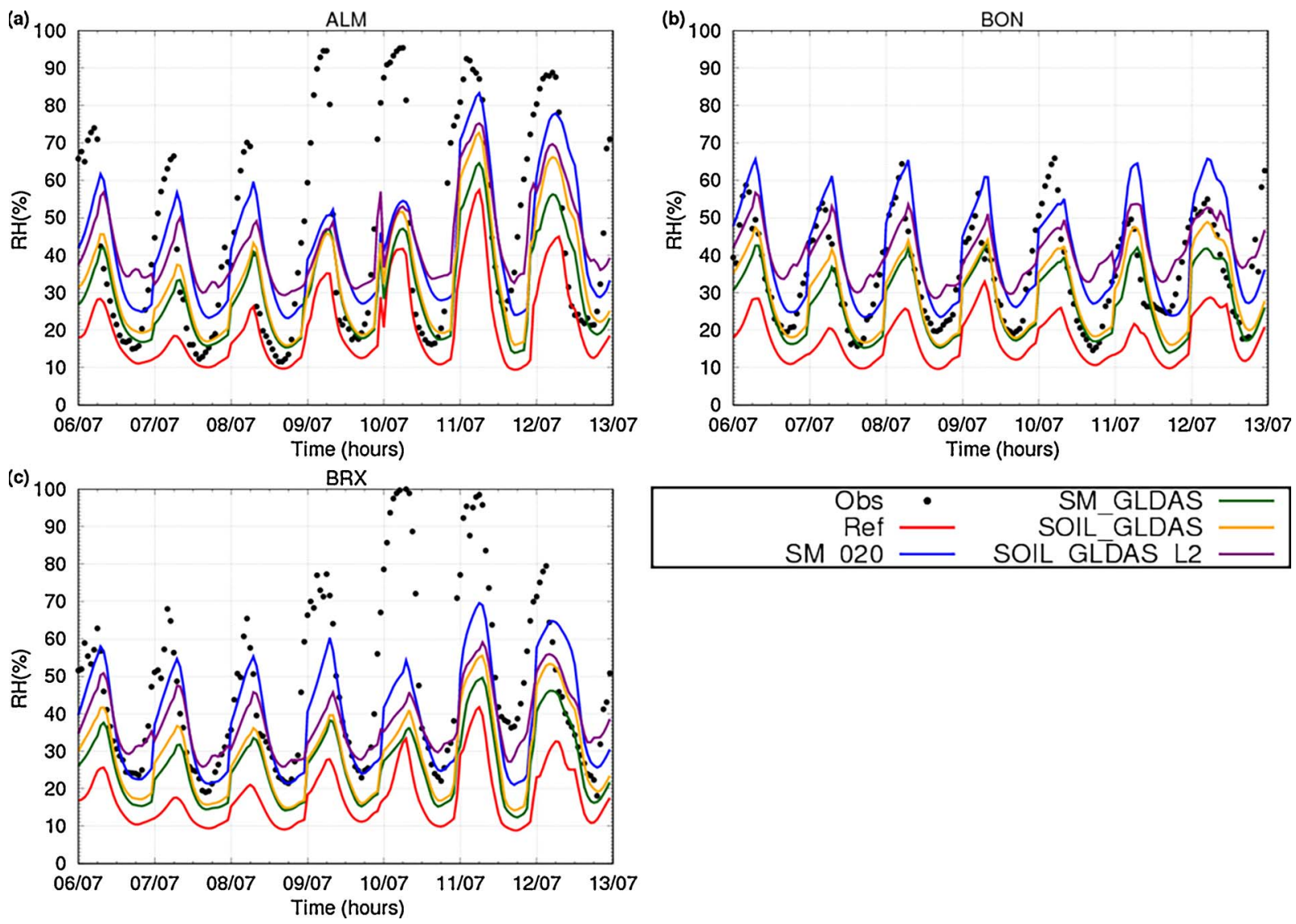

Fig. 6. Same as Fig. 2, but for the 2-m relative humidity (\%).

model has a greater amount of available moisture at the soil bottom, that is transported from the lower layers to the surface. If this is not the case, and a high SM distribution is performed near the surface (such as in SM_020), more latent heat and less sensible heat fluxes are available, leading to a decrease in the temperature and an increase in the relative humidity fields. In contrast, a low SM distribution applied to all soil levels (such as in Ref) yields a warm and drier bias due to an underestimation of the latent heat flux and the overestimation of the sensible heat flux. The relative available SM content in the corresponding soil levels seems to be rather well reproduced by the GLDAS product, thus yielding proper results in terms of the different evaluated weather parameters.

Figs. 4 and 5 show the observed wind field and that simulated by SOIL_GLDAS for the ALM and BON weather stations, respectively. The 6-8 July period is characterized by a Western synoptic advection, and it favours wind speeds at day time higher than $5 \mathrm{~m} \mathrm{~s}^{-1}$, while producing low atmospheric moisture over the area of study (Fig. 6). In addition, on 9 and 10 July, mesoscale circulations are well established over the area, where a clear transition is observed between the night and diurnal wind flows. In this case, not such high wind speeds are observed at day time as in the case of a Western synoptic advection. However, a significant shift in the atmospheric moisture between day and night is observed under mesoscale circulations, as a high moisture content is confined over the region during the night favoured by the nocturnal cooling (Fig. 2) and the low wind speed (Figs. 4 and 5). In general, RAMS reproduces the observed wind patterns very well. In terms of the wind speed, this model tends to be more windy than the observations over ALM, specially at night-time. On the other hand, RAMS is less windy than the observations over BON. The general Eastern synoptic advection established over the area of study is observed over ALM (Fig. 4c), and it is simulated by RAMS as well, capturing the observations really well, as shown in Fig. 4g. This is not the case over BON, where a dominant southwestern flow is developed during the day, that is really well captured by RAMS (Fig. $5 \mathrm{c}$ and $\mathrm{g}$ ). In the case of mesoscale circulations over BON (Fig. $5 \mathrm{~b}$ and f), although there is a shift between day and night in the model, the observations show a nocturnal southeastern wind flow, while the model simulates a northwestern component. Figs. 4 and 5 summarizes the results obtained by the model under the most predominant atmospheric summer conditions over the area of study, divided by synoptic principal components as well as considering the importance of mesoscale circulations during the summer over this region (Gómez et al., 2014c, 2015a). Although only the simulation results produced by SOIL_GLDAS are included in Figs. 4 and 5, markedly similar outcomes are obtained when using Ref, SM_020, SM_GLDAS and SOIL_GLDAS_L2 runs, with little differences among them in terms of the wind field (not shown).

If we focus on the relative humidity (Fig. 6), RAMS properly reproduces the observed values under the western synoptic advection. Under these atmospheric conditions, both SM_GLDAS and SOIL_GLDAS in general underestimates the observations. However, when mesoscale circulations are well developed over the area of study (9 and 10 July 2011) and also under an eastern synoptic advection (11 July 2011), RAMS in general tends to underestimate the corresponding measures at night-time (with bias that could be higher than $-40 \%$ depending on the station location), while they are better captured during the day (as indicated by a low bias, which indeed could reach values up to $-30 \%$, once again depending on the station location). Additionally, SOIL_GLDAS_L2 produces a moister bias at daytime over all weather stations in contrast to the other RAMS simulations, with SM_GLDAS and SOIL_GLDAS better capturing the observations during the day (Fig. 6). Considering the wind field in relation to the temperature at daytime, it has been found that western synoptic advections, with the highest wind speeds, produce a decreased 2-m temperature in comparison to that observed under mesoscale circulations (Fig. 2). In this latter case, 
(a)

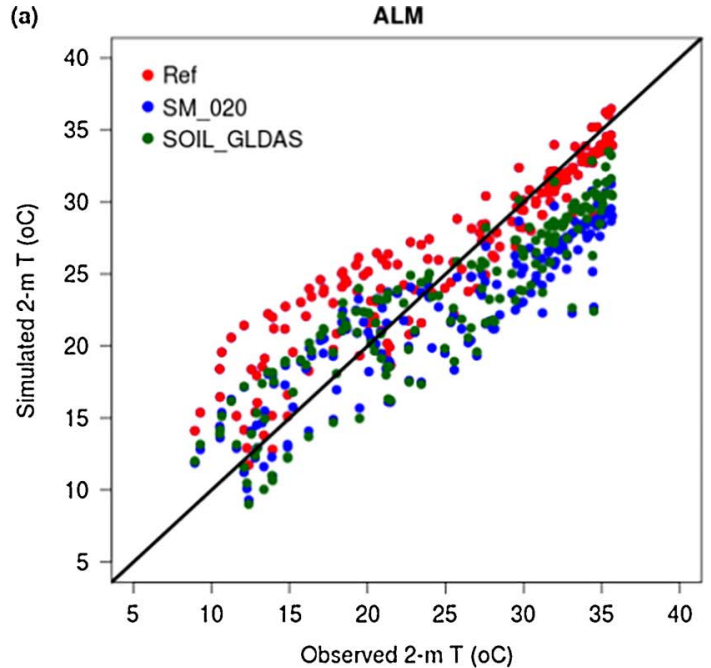

(c)

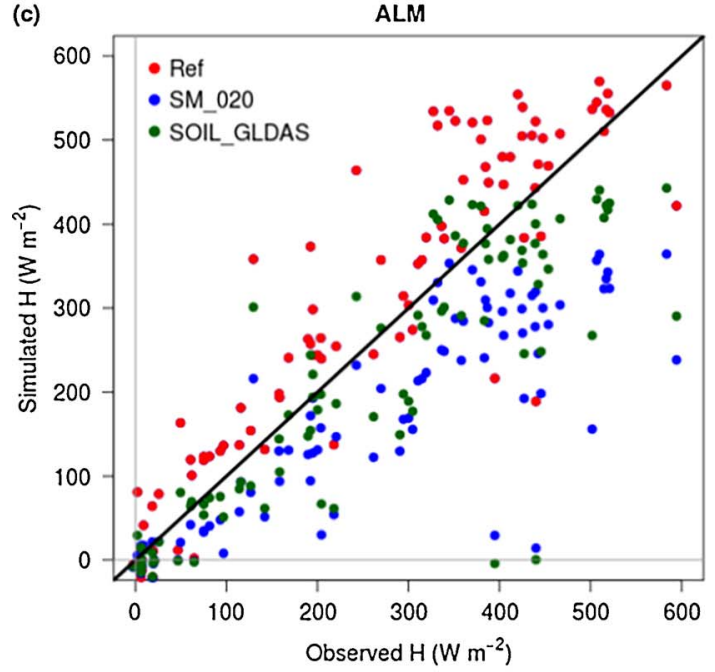

(e)

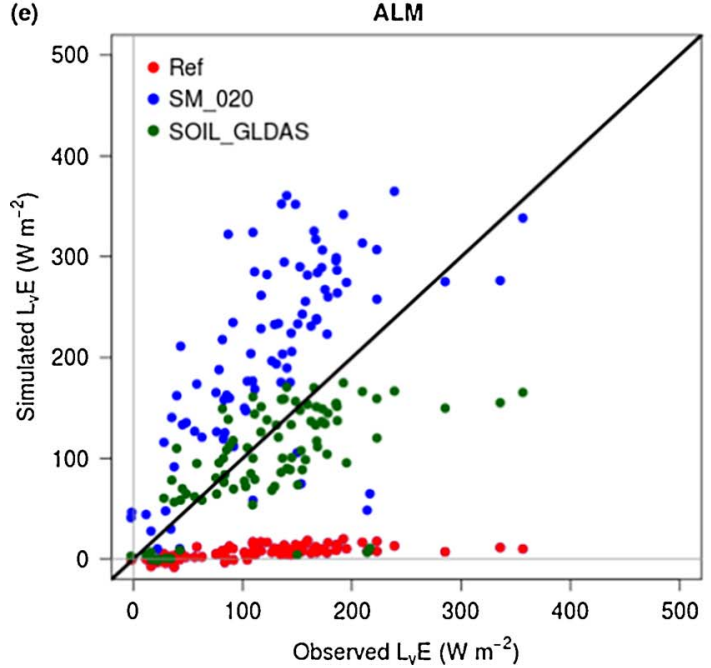

(b)

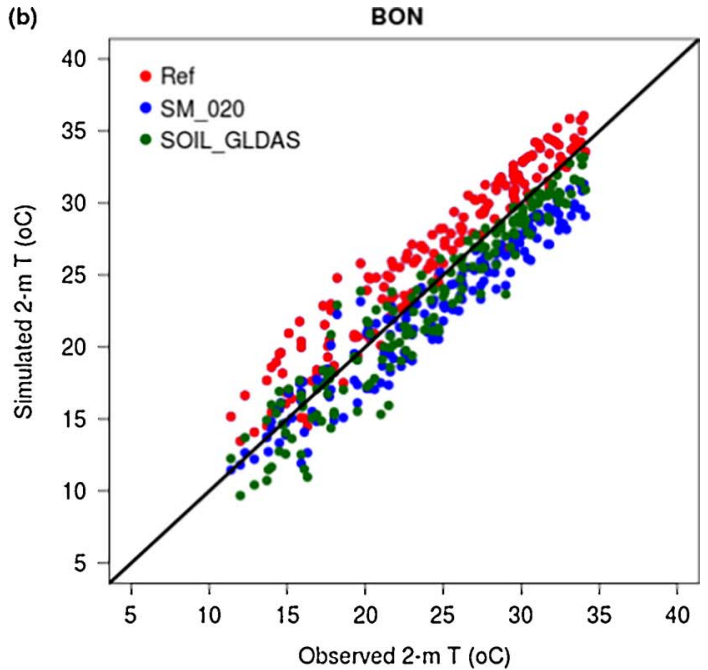

(d)

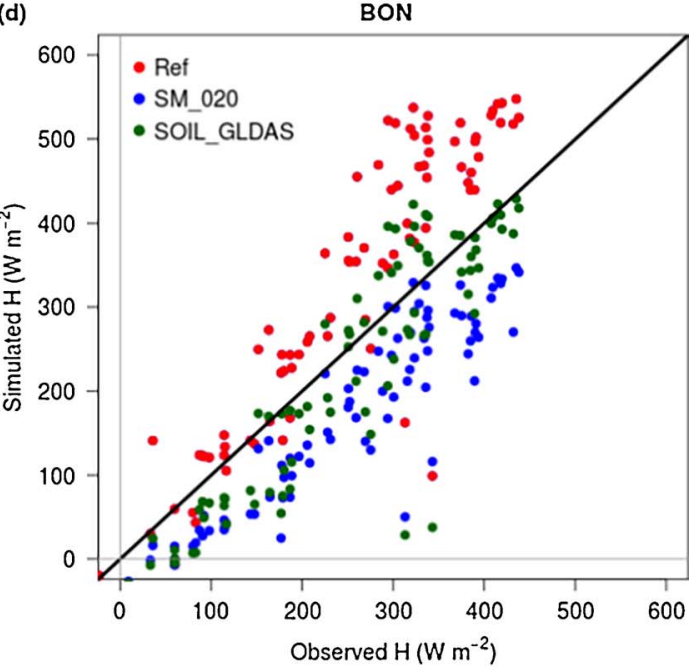

(i)

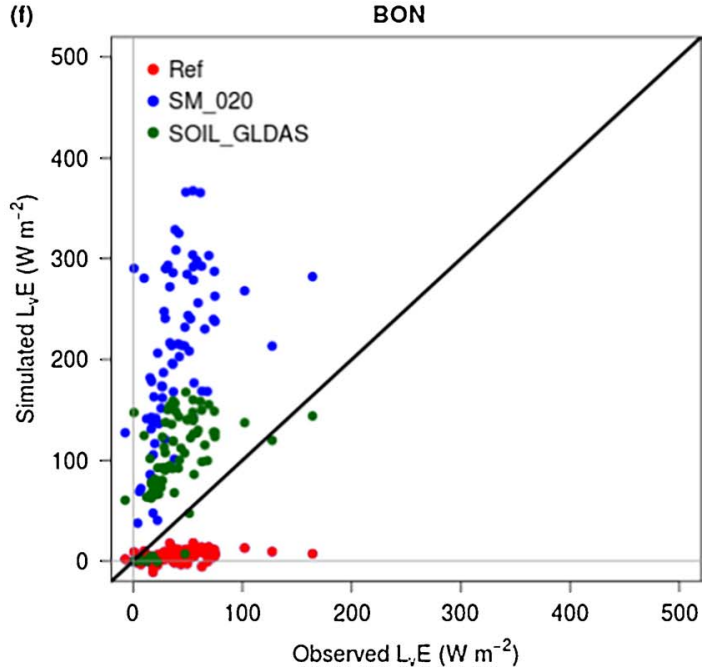

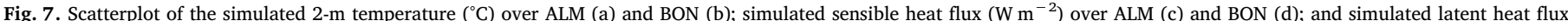
$\left(\mathrm{W} \mathrm{m}^{-2}\right.$ ) over ALM (e) and BON (f), versus the corresponding observed magnitude, considering the whole simulation period and the Ref, SM_020 and SOIL_GLDAS runs. 

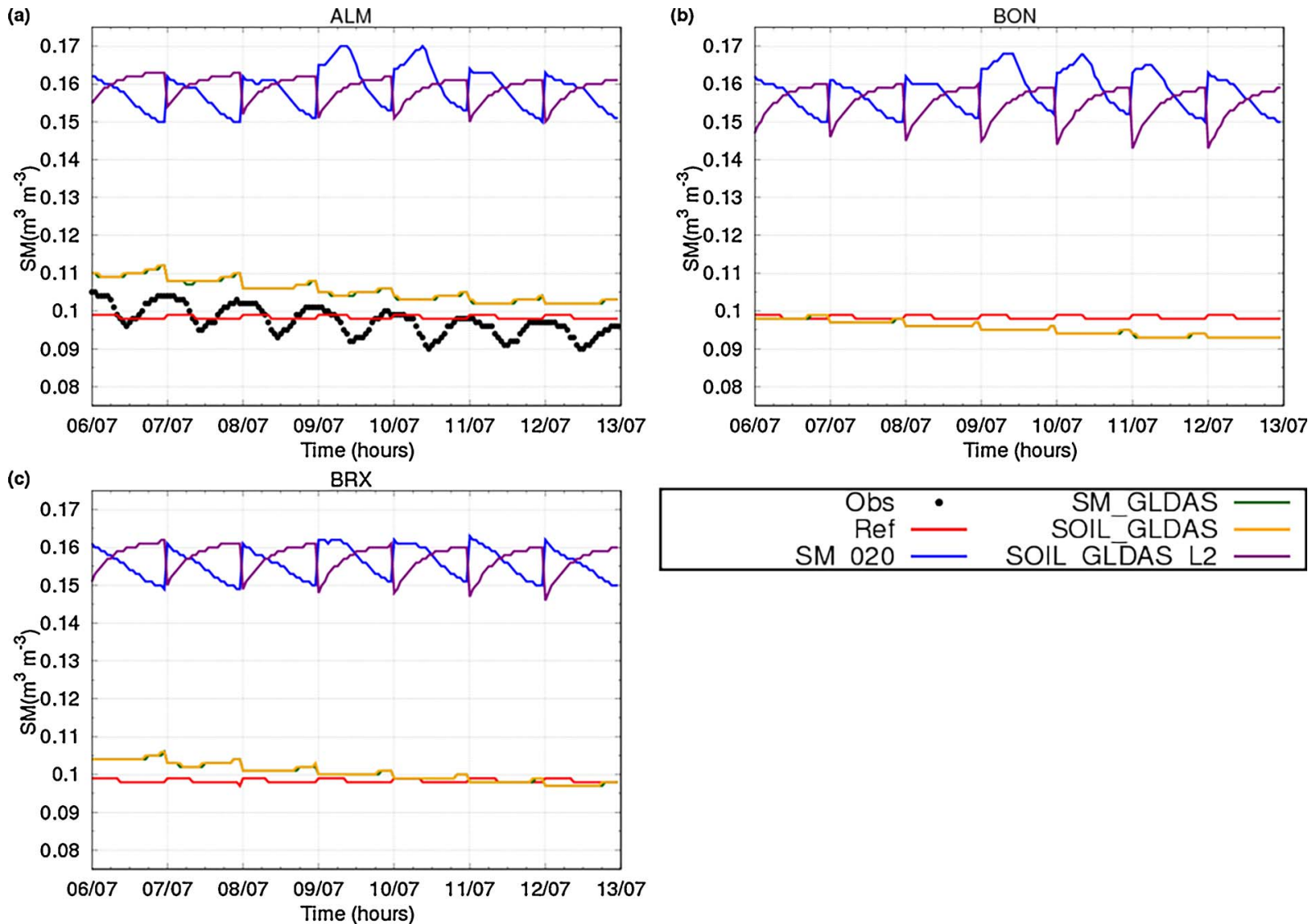

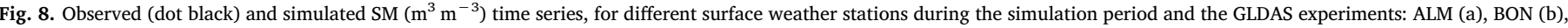
BRX (c).

higher temperatures together with lower wind speeds are observed. The general expectation assumes that transpiration rates normally increase with increased wind speeds, leading to colder temperatures. This general result is also shown in Fig. 2 for the different weather stations. Additionally, this figure displays how all RAMS simulations capture this relation between wind speed and temperature, considering the modulation in the transpiration rates provoked by the corresponding wind speeds shown in Figs. 4 and 5.

4.2. What is the role of the land use conditions in the performance of the short-term forecasts over the selected areas?

Coming back to the temperature and surface fluxes, note BON is characterized by a sparse vegetation environment, as well as BRX. However, considering the latter one, we highlight here that STSEB modelling results are obtained for a cultivated and very limited area which was well irrigated within the period of study, even though the weather station instruments are located outside this parcel. For this reason, the 2-m temperature shows a similar pattern to the other locations included in the current study, while the surface fluxes over BRX differ considerably from the values found over BON. Due to the irrigation conditions over BRX, the surface energy partitioning produces a higher latent heat flux and a lower sensible heat flux compared to those obtained over drier areas, such as BON. As a result, over BRX not only it is necessary to increase the initial SM in the lower soil levels, but also in the upper levels so as to reproduce the proper conditions of this reduced and well irrigated area. This has been achieved using the SM_020 simulation and especially using the SOIL_GLDAS_L2. In this second case, it seems that the lack of the upper SM is compensated by the deeper levels underground that can transport the corresponding moisture upwards. Due to the very reduced and confined irrigated area, the corresponding SM conditions are not reproduced by GLDAS as its resolution is not able to detect the corresponding changes, which are expected to be closer to those found over the location of the BRX weather station.

Contrasting the land use over ALM with BON, the first one corresponds to a well vegetated area (see Section 2). The differences obtained over ALM between the model and the observations in contrast to those found in other locations could be related to this issue, where the influence of the vegetation is of significant importance and it should be taken into account. Focusing on this weather station, Ref reproduces the observations of the daytime temperature very well, and better than the other simulations. In this regard, the other RAMS runs underestimate the recorded values over this location (with differences higher than $-4{ }^{\circ} \mathrm{C}$ ). On the other hand, the temperature diurnal cycle is notably reproduced on 9 and 10 July 2011, corresponding to a well established mesoscale circulation over the region, and capturing really well the daily temperature extremes. However, even though RAMS is able to reproduce the observed maximum temperature at ALM within the whole simulation period, the minimum temperature simulated by Ref configuration is overestimated under western synoptic advections (Fig. 2a). Considering the surface fluxes, Ref run reproduces very well the observed surface heat flux over ALM (Fig. 3a), while this run shows really low values of latent heat flux in comparison to the observations (Fig. 3b). This result is simulated for all station locations in general. On the other hand, although slightly underestimating the observations for some days within the simulation period, SM_GLDAS and SOIL_GLDAS reproduce rather well the observed surface fluxes over ALM as well (Fig. 3a and b). The use of the GLDAS soil parameters over ALM produces a compromise in the energy partitioning for the sensible and the latent heat fluxes. However, this compromise produces the mentioned underestimation of the 2-m temperature during the day. Finally, it is 

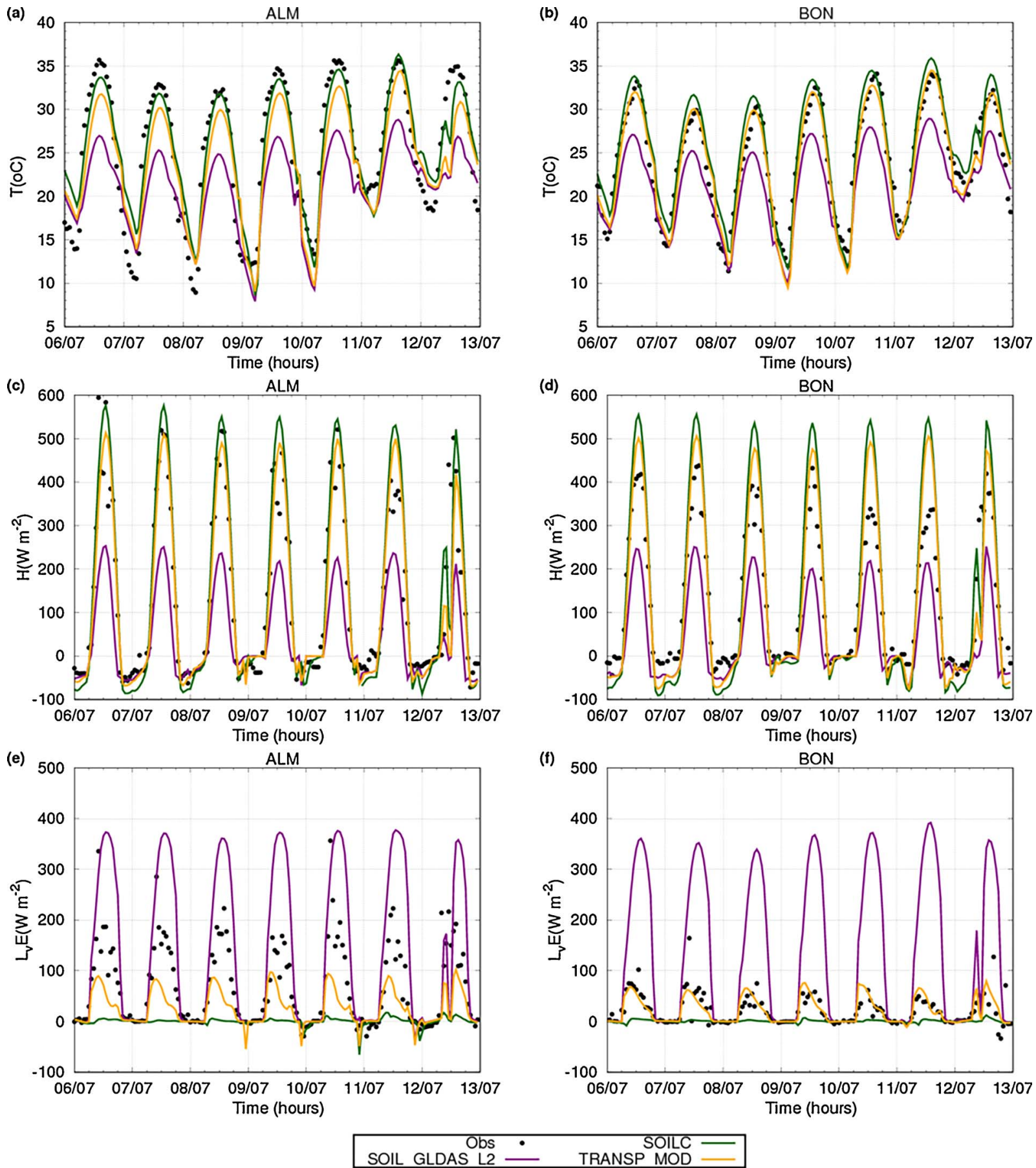

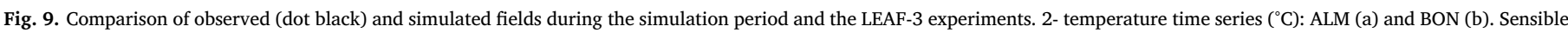
heat flux (W m $\left.{ }^{-2}\right)$ : ALM (c) and BON (d). Latent heat flux $\left(\mathrm{W} \mathrm{m}^{-2}\right)$ : ALM (e) and BON (f).

shown that an increase in the initial SM, such as SM_020, produces the inversion of the surface fluxes trend, thus significantly underestimating the observations related to the sensible heat flux and overestimating the latent heat flux, which is more marked including two additional soil layers in the RAMS simulation environment (SOIL_GLDAS_L2). In both cases, the moisture supply to the environment produces an increase in the available humidity (Fig. 6) while a significant cold bias is observed for the simulated 2-m temperature (Fig. 2). A summary of the results produced by Ref, SM_020 and SOIL_GLDAS simulation is included in Fig. 7 for both ALM and BON. This figure highlights the relationship between the observations and the simulation results in terms of the 2-m temperature and the surface turbulent fluxes, considering the whole simulation period. A better representation of the sensible heat flux together with a substantial underestimation in the latent heat flux seems the more plausible reason for the skillful agreement obtained in terms of the day-time 2-m temperature over ALM using the Ref simulation. On the other hand, even though the latent heat flux is still underestimated over BON using Ref, the general overestimation of the sensible heat flux seems to be the reason of the day-time temperature overestimation obtained over BON when using this RAMS simulation.

The increase supplied by SM_020 and SOIL_GLDAS_L2 in term of SM is well reflected in Fig. 8. Both SM_020 and SOIL_GLDAS_L2 produce an overestimation of the observations, with values higher that $50 \%$ compared to the other simulations and the observations. However, a moderate moistening of the soil, such as that introduced using SM_GLDAS and SOIL_GLDAS, reproduce the observations really well over ALM 


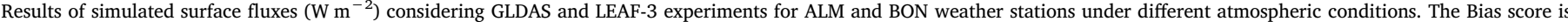

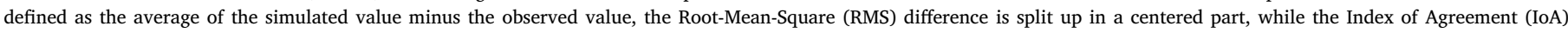
measures the degree to which a model's prediction is free of error. A value of 0 means complete disagreement while a value of 1 implies a perfect agreement.

\begin{tabular}{|c|c|c|c|c|c|c|c|c|c|c|c|c|}
\hline & \multicolumn{6}{|c|}{ ALM } & \multicolumn{6}{|c|}{ BON } \\
\hline & \multicolumn{3}{|l|}{$\mathrm{H}$} & \multicolumn{3}{|l|}{ LvE } & \multicolumn{3}{|l|}{$\mathrm{H}$} & \multicolumn{3}{|l|}{ LvE } \\
\hline & IoA & BIAS & RMS & IoA & BIAS & RMS & IoA & BIAS & RMS & IoA & BIAS & RMS \\
\hline & \multicolumn{12}{|c|}{ Western synoptic advection } \\
\hline SOIL_GLDAS & 0.9 & -50 & 60 & 0.8 & -30 & 40 & 1.0 & -15 & 50 & 0.5 & 60 & 30 \\
\hline SOILC & 1.0 & 40 & 60 & 0.4 & -130 & 60 & 0.9 & 60 & 70 & 0.4 & -50 & 30 \\
\hline \multirow[t]{2}{*}{ TRANSP_MOD } & 1.0 & -8 & 60 & 0.5 & -80 & 60 & 0.9 & 20 & 60 & 0.6 & -5 & 30 \\
\hline & \multicolumn{12}{|c|}{ Mesoscale circulation } \\
\hline SOIL_GLDAS & 0.9 & -60 & 90 & 0.8 & -19 & 60 & 1.0 & -40 & 40 & 0.4 & 70 & 40 \\
\hline SOILC & 0.9 & 20 & 90 & 0.4 & -120 & 70 & 0.8 & 90 & 80 & 0.4 & -30 & 16 \\
\hline \multirow[t]{2}{*}{ TRANSP_MOD } & 0.9 & -18 & 90 & 0.5 & -70 & 60 & 0.9 & 50 & 70 & 0.8 & 7 & 19 \\
\hline & \multicolumn{12}{|c|}{ Eastern synoptic advection } \\
\hline SOIL_GLDAS & 1.0 & 20 & 50 & 0.9 & -10 & 40 & 0.9 & 19 & 60 & 0.3 & 70 & 30 \\
\hline SOILC & 0.9 & 90 & 70 & 0.5 & -100 & 60 & 0.8 & 110 & 80 & 0.4 & -30 & 14 \\
\hline \multirow[t]{2}{*}{ TRANSP_MOD } & 0.9 & 60 & 60 & 0.6 & -60 & 50 & 0.8 & 90 & 70 & 0.8 & 6 & 14 \\
\hline & \multicolumn{12}{|c|}{ Western synoptic advection (Cloudy) } \\
\hline SOIL_GLDAS & 0.7 & -90 & 160 & 0.6 & -40 & 80 & 0.8 & -80 & 100 & 0.5 & 40 & 50 \\
\hline SOILC & 0.7 & 13 & 180 & 0.4 & -120 & 60 & 0.8 & 30 & 130 & 0.4 & -30 & 40 \\
\hline \multirow[t]{2}{*}{ TRANSP_MOD } & 0.7 & -60 & 170 & 0.5 & -80 & 70 & 0.8 & -30 & 120 & 0.5 & -0.9 & 40 \\
\hline & \multicolumn{12}{|c|}{ All atmospheric conditions } \\
\hline SOIL_GLDAS & 0.9 & -50 & 90 & 0.7 & -30 & 50 & 0.9 & -30 & 70 & 0.4 & 60 & 40 \\
\hline SOILC & 0.9 & 40 & 100 & 0.4 & -120 & 70 & 0.9 & 70 & 90 & 0.4 & -40 & 30 \\
\hline TRANSP_MOD & 0.9 & -8 & 100 & 0.5 & -80 & 60 & 0.9 & 30 & 80 & 0.7 & 0.05 & 30 \\
\hline
\end{tabular}

(Fig. 8a). Although measurements of SM are only provided for this location, similar qualitative results are found for BON and BRX (Fig. 8b and c). We must highlight at this point that LEAF-3 uses the "big leaf" approach for vegetated surfaces, where the assumption that a layer of vegetation overlaps a shaded soil is accepted. In this regard, the Normalized Difference Vegetation Index (NDVI), derived from satellite observations of vegetation greenness, is used to compute the vegetation LAI (Eq. (3)) based on the Fractional Photosynthetically Active Radiation (FPAR). A complete description of the procedure used to represent LAI vegetation in the LEAF model is included in Lu and Shuttleworth (2002).

\subsection{Can an increase transpiration improve the short-term forecasts over vegetated areas?}

Above RAMS was shown not to be able to adequately capture the 2$\mathrm{m}$ temperature daily evolution over vegetated areas, such as ALM, even though simulating the surface fluxes properly. We try to improve this results by means of two different approaches (see Section 3 as well), consisting of a modification in the LEAF core. In this model, available water from the moistest level in root zone is removed for transpiration, leading to a reduction in the soil water content and as a result of the released latent heat flux. The amount of available water content that can be removed depends on the SM content. If we focus on Fig. 3b, we can see that using the same parameterization to compute the water content used for transpiration, SM_020 and SOIL_GLDAS_L2 show still enough SM content to be released as latent heat flux in contrast for example to SOIL_GLDAS. Thus, we have used this water loss included in the LEAF sub-model to adjust the latent heat flux. Taking advantage of the general overestimation of the latent heat flux simulated when using the SOIL_GLDAS_L2 run, we have used this simulation to redefine the LEAF code in charge of computing the soil water loss used for transpiration. We have computed this water loss using two distinct methods, as indicated in Section 3. On the one hand, increasing the simulated transpiration (TRANSP_MOD) and, on the other hand, using the soil capacity as the maximum limit that can be removed from the available SM when computing the soil water loss (SOILC). In both cases, we are trying to increase the water loss used for transpiration as there seems to be an excess of this magnitude that leads to a greater release of latent heat flux compared to that observed (Fig. 3).

Fig. 9a shows the model results for the 2-m temperature using these two code modifications compared to the original SOIL_GLDAS_L2. This figure shows that although still producing a cold bias over ALM, TRANSP_MOD largely reduces the original cold bias produced by SOIL_GLDAS_L2. The temperature RMS difference included in Table 2 shows values lower than $2{ }^{\circ} \mathrm{C}$ both at night and day time using TRANSP_MOD over ALM, with RMS values of 1.1 and $1.0^{\circ} \mathrm{C}$ during the day under mesoscale and easterly circulations respectively. Additionally, the simulated sensible heat flux using TRANSP_MOD is increased adjusting the observations rather well (Fig. 9c). However, the latent heat flux undergoes a notable reduction in comparison with SOIL_GLDAS_L2, leading to an underestimation of the observed latent heat flux (Fig. 9e). Table 3 presents RMS values for TRANSP_MOD around $60-90 \mathrm{~W} \mathrm{~m}^{-2}$ for the sensible heat flux and around $50-60 \mathrm{~W} \mathrm{~m}^{-2}$ for the latent heat flux, depending on the atmospheric situation.

The decrease in the latent heat flux observed using TRANSP_MOD is even more deepened using SOILC run, with indeed low latent heat flux values, reminding those obtained for the Ref simulation (Fig. 3b), or even lower. However, SOILC captures the observed 2-m temperature really well with the corresponding balance in the sensible heat flux (Fig. 9a). The day-time temperature RMS difference for this simulation is $1.6,1.2$ and $1.3^{\circ} \mathrm{C}$ under the western synoptic advection, mesoscale circulation and eastern synoptic advection respectively, with sensible heat flux values of 60,90 and $70 \mathrm{~W} \mathrm{~m}^{-2}$ (Table 3).

Considering the results obtained for the vegetated area over ALM, it is necessary to notably reduce the latent heat flux so as to produce the corresponding sensible heat increase that leads to a proper representation of the observed 2-m temperature. Any raise in the latent heat flux reduces the sensible heat flux in the available energy partitioning, and produces a temperature cold bias.

The same behaviour is found over a poor and sparsely vegetated area such as BON. However, Fig. 9b shows that TRANSP_MOD run is extraordinary skilful in capturing the daily evolution of the 2-m 


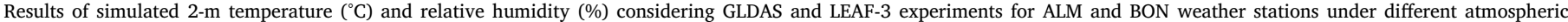
conditions.

\begin{tabular}{|c|c|c|c|c|c|c|c|c|c|c|c|c|}
\hline & \multicolumn{6}{|l|}{ ALM } & \multicolumn{6}{|c|}{ BON } \\
\hline & \multicolumn{3}{|l|}{$\mathrm{T}$} & \multicolumn{3}{|l|}{ RH } & \multicolumn{3}{|l|}{$\mathrm{T}$} & \multicolumn{3}{|l|}{ RH } \\
\hline & IoA & BIAS & RMS & IoA & BIAS & RMS & IoA & BIAS & RMS & IoA & BIAS & RMS \\
\hline & \multicolumn{12}{|c|}{ Western synoptic advection } \\
\hline SOIL_GLDAS - Day & 0.8 & -4 & 2 & 0.8 & 4 & 10 & 1.0 & -1.6 & 1.2 & 1.0 & -0.8 & 3 \\
\hline SOIL_GLDAS - Night & 0.9 & 3 & 2 & 0.6 & -21 & 12 & 1.0 & 0.5 & 1.4 & 0.7 & -12 & 5 \\
\hline SOILC - Day & 1.0 & -1.3 & 1.6 & 0.6 & -9 & 11 & 1.0 & 1.2 & 1.6 & 0.6 & -13 & 5 \\
\hline SOILC - Night & 0.8 & 4 & 2 & 0.5 & -30 & 14 & 0.9 & 2 & 1.5 & 0.5 & -25 & 9 \\
\hline TRANSP_MOD - Day & 0.9 & -3 & 1.9 & 0.9 & 1.0 & 9 & 1.0 & -0.6 & 1.5 & 1.0 & -4 & 2 \\
\hline \multirow[t]{2}{*}{ TRANSP_MOD - Night } & 0.9 & 3 & 2 & 0.6 & -20 & 10 & 1.0 & 1.0 & 1.3 & 0.7 & -13 & 5 \\
\hline & \multicolumn{12}{|c|}{ Mesoscale circulation } \\
\hline SOIL_GLDAS - Day & 0.9 & -5 & 1.0 & 0.8 & -3 & 17 & 0.9 & -2 & 1.6 & 1.0 & 0.4 & 4 \\
\hline SOIL_GLDAS - Night & 1.0 & -1.2 & 1.9 & 0.5 & -40 & 14 & 1.0 & -1.9 & 0.8 & 0.7 & -13 & 7 \\
\hline SOILC - Day & 1.0 & -1.9 & 1.2 & 0.7 & -13 & 16 & 1.0 & 0.6 & 2 & 0.7 & -10 & 6 \\
\hline SOILC - Night & 1.0 & 0.5 & 1.9 & 0.5 & -50 & 14 & 1.0 & -0.17 & 0.9 & 0.5 & -20 & 10 \\
\hline TRANSP_MOD - Day & 0.9 & -4 & 1.1 & 0.8 & -6 & 16 & 1.0 & -1.1 & 1.9 & 1.0 & -1.9 & 4 \\
\hline \multirow[t]{2}{*}{ TRANSP_MOD - Night } & 1.0 & -0.8 & 2 & 0.5 & -40 & 14 & 1.0 & -1.3 & 1.0 & 0.7 & -14 & 7 \\
\hline & \multicolumn{12}{|c|}{ Eastern synoptic advection } \\
\hline SOIL_GLDAS - Day & 0.9 & -3 & 0.9 & 0.9 & -7 & 9 & 1.0 & -1.1 & 0.8 & 0.8 & -0.12 & 7 \\
\hline SOIL_GLDAS - Night & 1.0 & -0.4 & 1.5 & 0.6 & -30 & 8 & 1.0 & -1.2 & 1.8 & 0.5 & -13 & 8 \\
\hline SOILC - Day & 1.0 & -0.3 & 1.3 & 0.8 & -20 & 6 & 1.0 & 1.4 & 1.1 & 0.4 & -14 & 4 \\
\hline SOILC - Night & 0.9 & 0.6 & 2 & 0.4 & -40 & 9 & 1.0 & -0.3 & 1.5 & 0.3 & -30 & 4 \\
\hline TRANSP_MOD - Day & 1.0 & -1.9 & 1.0 & 0.9 & -10 & 9 & 1.0 & -0.06 & 1.0 & 0.8 & -3 & 8 \\
\hline \multirow[t]{2}{*}{ TRANSP_MOD - Night } & 0.9 & -0.04 & 1.7 & 0.6 & -30 & 10 & 1.0 & -0.6 & 1.5 & 0.5 & -14 & 8 \\
\hline & \multicolumn{12}{|c|}{ Western synoptic advection (Cloudy) } \\
\hline SOIL_GLDAS - Day & 0.6 & -5 & 3 & 0.8 & 9 & 14 & 0.9 & -1.3 & 1.8 & 0.9 & 4 & 4 \\
\hline SOIL_GLDAS - Night & 0.8 & 2 & 2 & 0.7 & -30 & 12 & 0.7 & 0.3 & 2 & 0.5 & -14 & 11 \\
\hline SOILC - Day & 0.9 & -2 & 3 & 0.9 & -7 & 11 & 0.9 & 1.5 & 1.8 & 0.7 & -10 & 5 \\
\hline SOILC - Night & 0.7 & 4 & 1.6 & 0.6 & -40 & 13 & 0.7 & 3 & 1.6 & 0.4 & -30 & 7 \\
\hline TRANSP_MOD - Day & 0.7 & -5 & 3 & 0.8 & 8 & 14 & 0.9 & -0.7 & 1.9 & 1.0 & 1.9 & 4 \\
\hline \multirow[t]{2}{*}{ TRANSP_MOD - Night } & 0.8 & 3 & 1.8 & 0.7 & -30 & 12 & 0.7 & 0.6 & 3 & 0.5 & -15 & 12 \\
\hline & \multicolumn{12}{|c|}{ All atmospheric conditions } \\
\hline SOIL_GLDAS - Day & 0.8 & -4 & 2 & 0.8 & 1.0 & 14 & 1.0 & -1.6 & 1.4 & 1.0 & 0.3 & 4 \\
\hline SOIL_GLDAS - Night & 0.9 & 1.0 & 3 & 0.6 & -30 & 14 & 1.0 & -0.4 & 1.9 & 0.7 & -13 & 7 \\
\hline SOILC - Day & 1.0 & -1.4 & 1.8 & 0.8 & -11 & 13 & 1.0 & 1.1 & 1.8 & 0.7 & -12 & 5 \\
\hline SOILC - Night & 0.9 & 3 & 3 & 0.5 & -40 & 15 & 1.0 & 1.3 & 1.9 & 0.5 & -20 & 8 \\
\hline TRANSP_MOD - Day & 0.9 & -3 & 2 & 0.9 & -1.5 & 13 & 1.0 & -0.7 & 1.6 & 0.9 & -2 & 4 \\
\hline TRANSP_MOD - Night & 0.9 & 1.4 & 3 & 0.6 & -30 & 14 & 1.0 & 0.05 & 1.9 & 0.7 & -14 & 7 \\
\hline
\end{tabular}

temperature. In this regard, an RMS difference of 1.5 and $1.3^{\circ} \mathrm{C}$ is obtained under the western synoptic advection both at night and day time, respectively (Table 2). The same can be said for TRANSP_MOD and for the latent heat flux, where an RMS of 19 and $14 \mathrm{~W} \mathrm{~m}^{-2}$ and Bias of 7 and $6 \mathrm{~W} \mathrm{~m}^{-2}$ are obtained under the mesoscale and eastern synoptic conditions, respectively (Fig. of and Table 3).

Fig. 10c and d shows the contrast of the observed 2-m temperature and modelled by SOILC and TRANSP_MOD runs with the canopy temperature provided by the model for each one of these simulations. As expected, both temperatures are very similar over BON. However, more differences are obtained over ALM, with canopy temperatures being larger than 2-m temperatures. In this case, the still cold bias found during the day using TRANSP_MOD considering this magnitude is remarkably reduced applying the canopy temperature (Fig. 10c). Similar results can be described for SOILC simulation, where the canopy temperature remarkably reproduces the observed near-surface temperature field over ALM. On the other hand, if we focus on the SM within the upper soil level, alike results are obtained contrasting ALM with BON weather locations. Even though no observations are available for SM magnitude over BON, the observations over ALM present a drier soil using SOILC simulation while a moister soil is obtained for TRANSP_MOD.

\section{Conclusions}

We have shown that the incorporation of heterogeneous soil parameters derived from LSM models into a mesoscale model can improve the results obtained by simple using homogeneous initializations. In the current study, we have used the GLDAS version 1 Noah uncoupled LSM and the RAMS mesoscale model.

Originally, the initialization of RAMS based on a low SM field applied to all soil levels produces a general warm bias over poor and sparcely vegetated areas, while the day-time temperature simulated using this SM configuration yields really skilfull results during the day over well vegetated regions. A moister SM initial field adopted in all soil levels reverses this trend, thus causing a cold temperature bias when comparing the modelling results with the observations. Incorporating GLDAS SM produces a situation which is in between the two homogeneous SM extremes for all surface variables. It seems that GLDAS is able to provide SM properly, and the simulated results in this case better reproduce the observations for the different evaluated sensible surface variables. On the other hand, ingesting the GLDAS ST into RAMS lowers the simulated temperature producing more adjusted results, especially under mesoscale circulations. The application of this specific model configuration produces really skilful results over sparsely vegetated areas. However, the model shows more difficulties in reproducing the observations over well vegetated areas. Over this region, it has been found that using the canopy temperature can improve 

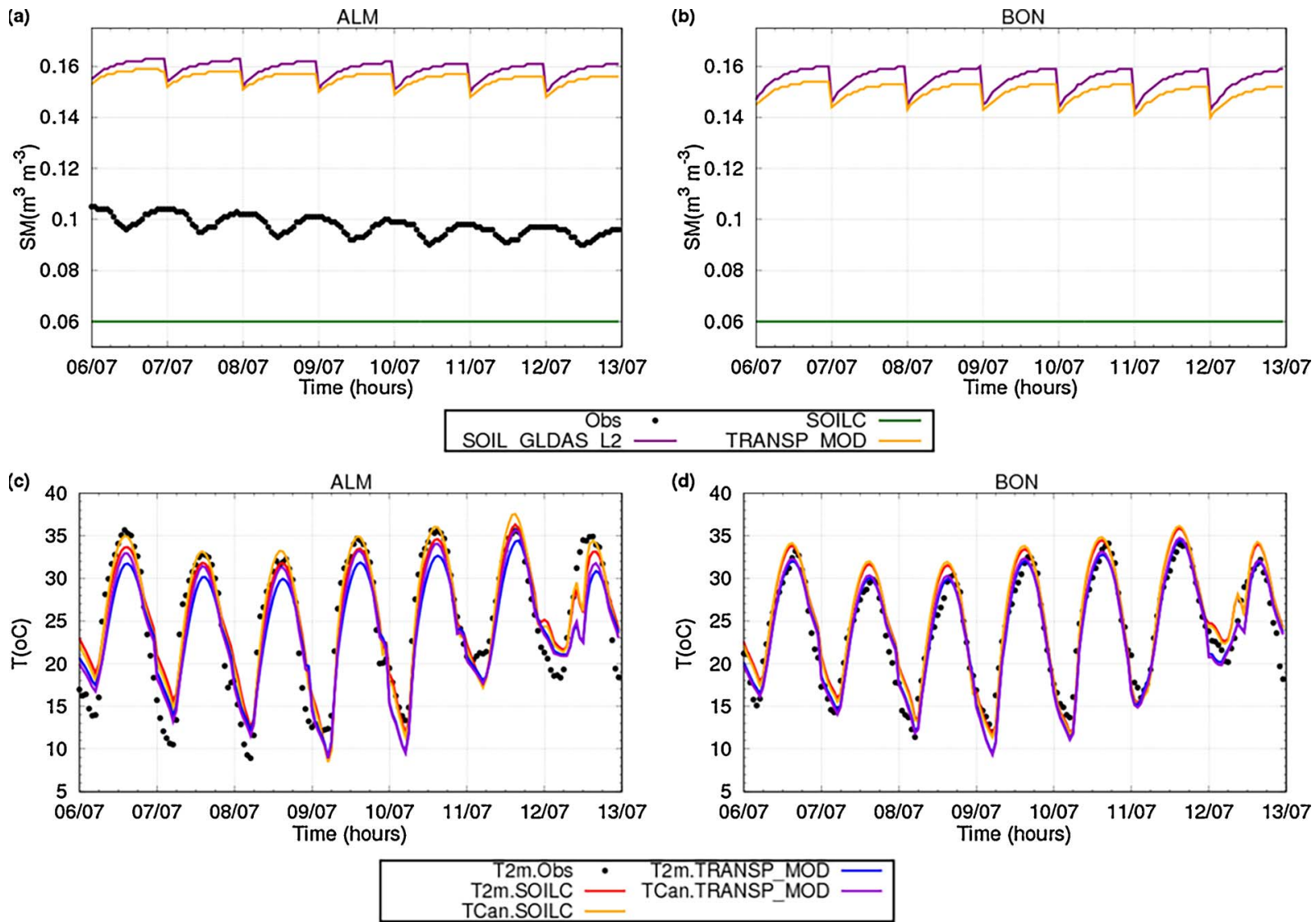

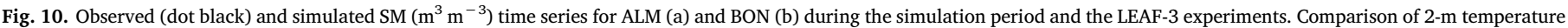
$\left({ }^{\circ} \mathrm{C}\right)$ with canopy temperature $\left({ }^{\circ} \mathrm{C}\right)$ over ALM (c) and BON (d).

the simulation of the temperature field, thus skilfully reproducing the observations.

We have investigated the RAMS outcomes when more levels reach deeper underground. In this case, the more available moisture provided by these additional levels is transported from the deeper soil levels to the surface, thus yielding a significant cold bias in terms of temperature while the simulated latent heat flux shows very high values in comparison to the observations. However, this additional available moisture could be used in the surface energy partitioning in order to reduce the differences between the model and the measurements. In this sense, additional sensitivity tests have shown that removing the available SM content by an increasing transpiration reduces these differences in all stations. A compromise needs to be achieved between the sensible and the latent heat fluxes over vegetated areas in order to better reproduce the first one and thus the temperature field, the model needs to reduce the available moisture and therefore the latent heat flux.

The results found in the current study significantly improve those previously found over the Western Mediterranean coast, using the low SM field in the current Ref configuration (Gómez et al., 2015a,b, 2016b). SM is a key magnitude in many processes of the biosphere and the climate system, and plays a crucial role in the interface between soil, vegetation, and the atmosphere. We have shown that a suitable representation of the initial SM field is of significant importance in mesoscale modelling in order to produce skillful meteorological and surface energy fluxes forecasts. Additionally, transpiration, which is related to soil dryness, should be taken into account we well. Therefore, the initial SM field should be first verified when configuring and running a mesoscale model.

Studies focused on land-atmosphere coupling, such as the one conducted by Dirmeyer et al. (2013), has stated that this coupling is expected to be reinforced in the future throughout most of the globe, meaning a greater control by soil moisture variations on surface fluxes and the lower troposphere. The outcomes achieved in the current work regarding this land-atmosphere coupling are shown to be remarkably skilful. This is really encouraging considering the operational production of meteorological information of significant importance for a wide range of relevant applications, such as modelling for atmospheric, hydrological, agricultural and ecological purposes. In this regard, additional experiments should be conducted over longer periods of time with the aim of achieving a more definitive assertion.

\section{Acknowledgements}

This work has been funded by the Regional Government of Valencia through the project PROMETEOII/2014/086. NCEP is acknowledged for providing the FNL analysis data for RAMS initialization. The GLDAS data used in this study were acquired as part of the mission of NASA's Earth Science Division and archived and distributed by the Goddard Earth Sciences (GES) Data and Information Services Center (DISC) are acknowledged by disseminating the GLDAS data. The Spanish Ministry of Economy and Competitiveness with co-funding from the European Development Regional Fund (MINECO/FEDER, UE; Project AGL201455658-R, FORESTRENGTH), and the Education, Culture and Sports Department of the Castilla-La Mancha Regional Council with cofunding from the European Development Regional Fund (FEDER) (Project PEIC-2014- 002-P, ECOFLUX III) are acknowledged for funding the acquisition of surface fluxes data for RAMS validation. Finally, we thank the three anonymous reviewers for their constructive feedback on the manuscript. 


\section{References}

Angevine, W.M., Bazile, E., Legain, D., Pino, D., 2014. Land surface spinup for episodic modeling. Atmos. Chem. Phys. 14, 8165-8172. http://dx.doi.org/10.5194/acp-148165-2014.

Avissar, R., Pielke, R.A., 1989. A parameterization of heterogeneous land surfaces for atmospheric numerical models and its impact on regional meteorology. Mon. Weather Rev. 117, 2113-2136. http://dx.doi.org/10.1175/1520-0493(1989) $117<2113$ :APOHLS > 2.0.CO;2.

Betts, A.K., 2009. Land-surface-atmosphere coupling in observations and models. J. Adv. Model. Earth Syst. 1, 4. http://dx.doi.org/10.3894/JAMES.2009.1.4.

Burgin, M.S., Colliander, A., Njoku, E.G., Chan, S.K., Cabot, F., Kerr, Y.H., Bindlish, R., Jackson, T.J., Entekhabi, D., Yueh, S.H., 2017. A comparative study of the SMAP passive soil moisture product with existing satellite-based soil moisture products. IEEE Trans. Geosci. Remote Sens. 55 (5), 2959-2971. http://dx.doi.org/10.1109/ TGRS.2017.2656859.

Castro, C., Cheng, W., Beltrán, A., Marshall Jr., C., Pielke Sr., R., Cotton, W., 2002. The incorporation of the Kain-Fritsch cumulus parameterization scheme in RAMS with a terrain-adjusted trigger function. In: Fifth RAMS Users Workshop. Santorini Island, Greece, 29 September-October 3. pp. 2002.

Chen, C., Cotton, W.R., 1983. A one-dimensional simulation of the stratocumulus-capped mixed layer. Boundary-Layer Meteorol. 25, 289-321. http://dx.doi.org/10.1007/ BF00119541.

Clapp, R.B., Hornberger, G.M., 1978. Empirical equations for some soil hydraulic properties. Water Resour. Res. 14 (4), 601-604. http://dx.doi.org/10.1029/ WR014i004p00601.

Cotton, W.R., Pielke, R.A.S., Walko, R.L., Liston, G.E., Tremback, C.J., Jiang, H., McAnelly, R.L., Harrington, J.Y., Nicholls, M.E., Carrio, G.G., McFadden, J.P., 2003. RAMS 2001: Current status and future directions. Meteorol. Atmos. Phys. 82 (1-4), 5-29. http://dx.doi.org/10.1007/s00703-001-0584-9.

Daniels, E., Hutjes, R., Lenderink, G., Ronda, R., Holtslag, A., 2015. Land surface feedbacks on spring precipitation in the Netherlands. J. Hydrometeor. 16, 232-243. http://dx.doi.org/10.1175/JHM-D-14-0072.1.

De Goncalves, L.G.G., Shuttleworth, W.J., Chou, S.C., Xue, Y., Houser, P.R., Toll, D.L. Marengo, J., Rodell, M., 2006. Impact of different initial soil moisture fields on Eta model weather forecasts for South America. J. Geophys. Res. 111, D17102. http://dx. doi.org/10.1029/2005JD006309.

Dillon, M.E., Collini, E.A., Ferreira, L.J., 2016. Sensitivity of WRF short-term forecasts to different soil moisture initializations from the GLDAS database over South America in March 2009. Atmos. Res. 167, 196-207. http://dx.doi.org/10.1016/j.atmosres.2015. 07.022 .

Dirmeyer, P., Halder, S., 2016. Sensitivity of numerical weather forecasts to initial soil moisture variations in CFSv2. Weather Forecasting 31, 1973-1983. http://dx.doi. org/10.1175/WAF-D-16-0049.1.

Dirmeyer, P.A., Cash, B.A., Kinter III, J.L., Stan, C., Jung, T., Marx, L., Towers, P., Wedi, N., Adams, J.M., Altshuler, E.L., Huang, B., Jin, E.K., Manganello, J., 2012. Evidence for enhanced land-atmosphere feedback in a warming climate. J. Hydrometeorol. 13, 981-995. http://dx.doi.org/10.1175/JHM-D-11-0104.1.

Dirmeyer, P.A., Jin, Y., Singh, B., Yan, X., 2013. Trends in land-atmosphere interactions from CMIP5 simulations. J. Hydrometeorol. 14, 829-849. http://dx.doi.org/10. 1175/JHM-D-12-0107.1.

Dirmeyer, P.A., Wang, Z., Mbuh, M.J., Norton, H.E., 2014. Intensified land surface control on boundary layer growth in a changing climate. Geophys. Res. Lett. 41, 1290-1294. http://dx.doi.org/10.1002/2013GL058826.

Entekhabi, D., Njoku, E.G., O'Neill, P.E., Kellogg, K.H., Crow, W.T., Edelstein, W.N., Entin, J.K., Goodman, S.D., Jackson, T.J., Johnson, J., Kimball, J., Piepmeier, J.R., Koster, R.D., Martin, N., McDonald, K.C., Moghaddam, M., Moran, S., Reichle, R., Shi, J.C., Spencer, M.W., Thurman, S.W., Tsang, L., Van Zyl, J., 2010. The soil moisture active passive (SMAP) mission. Proc. IEEE 98 (5), 704-716. http://dx.doi.org/10. 1109/JPROC.2010.2043918.

FAO, 1988. FAO/Unesco Soil Map of TheWorld, Revised Legend,With Corrections and Updates. Reprinted with Updates as Technical Paper 20. ISRIC, Wageningen, Netherlands 1997 (1988)

Ferguson, C.R., Wood, E.F., Vinukollu, R.K., 2012. A global intercomparison of modeled and observed land-atmosphere coupling. J. Hydrometeorol. 13, 749-784. http://dx. doi.org/10.1175/JHM-D-11-0119.1.

Gómez, I., Estrela, M.J., Caselles, V., 2014a. Operational forecasting of daily summer maximum and minimum temperatures in the Valencia Region. Nat. Hazards 70 (2), 1055-1076. http://dx.doi.org/10.1007/s11069-013-0861-1.

Gómez, I., Caselles, V., Estrela, M.J., 2014b. Real-time weather forecasting in the Western Mediterranean Basin: an application of the RAMS model. Atmos. Res. 139, 71-89. http://dx.doi.org/10.1016/j.atmosres.2014.01.011.

Gómez, I., Caselles, V., Estrela, M.J., Niclòs, R., 2014c. RAMS-forecasts comparison of typical summer atmospheric conditions over the Western Mediterranean coast. Atmos. Res. 145-146 (130-151). http://dx.doi.org/10.1016/j.atmosres.2014.03. 018.

Gómez, I., Estrela, M.J., Caselles, V., 2015a. Verification of the RAMS-based operational weather forecast system in the Valencia Region: a seasonal comparison. Nat. Hazards 75 (2), 1941-1958. http://dx.doi.org/10.1007/s11069-014-1408-9.

Gómez, I., Caselles, V., Estrela, M.J., 2015b. Impacts of soil moisture content on simulated mesoscale circulations during the summer over eastern Spain. Atmos. Res. 164-165 (9-26). http://dx.doi.org/10.1016/j.atmosres.2015.04.015.

Gómez, I., Caselles, V., Estrela, M.J., 2016a. Seasonal characterization of solar radiation estimates obtained from a MSG-SEVIRI-derived dataset and a RAMS-based operational forecasting system over the western mediterranean coast. Remote Sens. 8, 46.
Gómez, I., Ronda, R.J., Caselles, V., Estrela, M.J., 2016b. Implementation of non-local boundary layer schemes in the Regional Atmospheric Modeling System and its impact on simulated mesoscale circulations. Atmos. Res. 180, 24-41. http://dx.doi.org/10. 1016/j.atmosres.2016.04.020.

Gómez, I., Caselles, V., Estrela, M.J., Niclòs, R., 2016c. Impact of initial soil temperature derived from remote sensing and numerical weather prediction datasets on the simulation of extreme heat events. Remote Sens. 8, 589.

Gallego-Elvira, B., Taylor, C.M., Harris, P.P., Ghent, D., Veal, K.L., Folwell, S.S., 2016 Global observational diagnosis of soil moisture control on the land surface energy balance. Geophys. Res. Lett. 43, 2623-2631. http://dx.doi.org/10.1002/ 2016 GL068178.

García Morote, F.A., López Serrano, F.R., Andrés, M., Rubio, E., González Jiménez, J.L., de las Heras, J., 2012. Allometries, biomass stocks and biomass allocation in the thermophilic Spanish juniper woodlands of Southern Spain. For. Ecol. Manag. 270, 85-93. http://dx.doi.org/10.1016/j.foreco.2012.01.007.

Hirsch, A.L., Pitman, A.J., Kala, J., 2014. The role of land cover change in modulating the soil moisture-temperature land-atmosphere coupling strength over Australia. Geophys. Res. Lett. 41 (16), 5883-5890. http://dx.doi.org/10.1002/2014GL061179.

Hong, S., Noh, Y., Dudhia, J., 2006. A new vertical diffusion package with an explicit treatment of entrainment processes. Mon. Wea. Rev. 134 (9), 2318-2341. http://dx. doi.org/10.1175/MWR3199.1.

Juang, J.-Y., Katul, G.G., Porporato, A., Stoy, P.C., Siqueira, M.S., Detto, M., Kim, H.-S., Oren, R., 2007a. Eco-hydrological controls on summertime convective rainfall triggers. Glob. Chang. Biol. 13 (4), 887-896. http://dx.doi.org/10.1111/j.1365-2486. 2007.01315.x.

Juang, J.-Y., Porporato, A., Stoy, P.C., Siqueira, M.S., Oishi, A.C., Detto, M., Kim, H.-S., Katul, G.G., 2007b. Hydrologic and atmospheric controls on initiation of convective precipitation events. Water Resour. Res. 43 (3), W03421. http://dx.doi.org/10.1029/ 2006 WR004954.

Kalverla, P., Duine, G., Steeneveld, G., Hedde, T., 2016. Evaluation of the weather research and forecasting model in the durance valley complex terrain during the KASCADE field campaign. J. Appl. Meteor. Climatol. 55, 861-882. http://dx.doi.org/ 10.1175/JAMC-D-15-0258.1.

Kerr, Y.H., Waldteufel, P., Wigneron, J.-P., Delwart, S., Cabot, F., Boutin, J., Escorihuela, M.-J., Font, J., Reul, N., Gruhier, C., Juglea, S.E., Drinkwater, M.R., Hahne, A., Martín-Neira, M., Mecklenburg, S., 2010. The SMOS mission: new tool for monitoring key elements of the global water cycle. Proc. IEEE 98 (5), 666-687. http://dx.doi. org/10.1109/JPROC.2010.2043032.

Koster, R.D., Zhichang, G., Rongqian, Y., Dirmeyer, P., Kenneth, M., Puma, M., 2009. On the nature of soil moisture in land surface models. J. Clim. 22, 4322-4335. http://dx. doi.org/10.1175/2009JCLI2832.1.

López-Serrano, F.R., Martínez-García, E., Dadi, T., Rubio, E., García-Morote, F.A., LucasBorja, M.E., Andrés-Abellán, M., 2015. Biomass growth simulations in a natural mixed forest stand under different thinning intensities by 3-PG process-based model. Eur. J. For. Res. 134 (1), 167-185. http://dx.doi.org/10.1007/s10342-014-0841-3.

López-Serrano, F.R., Rubio, E., Dadi, T., Moya, D., Andrés-Abellán, M., García-Morote, F.A., Miettinen, H., Martínez-García, E., 2016. Influences of recovery from wildfire and thinning on soil respiration of a Mediterranean mixed forest. Sci. Total Environ. 573, 1217-1231. http://dx.doi.org/10.1016/j.scitotenv.2016.03.242.

López-Urrea, R., Martín de Santa Olalla, F., Fabeiro, C., Moratalla, A., 2006. Testing evapotranspiration equations using lysimeter observations in a semiarid climate. Agric. Water Manage. 85, 15-26. http://dx.doi.org/10.1016/j.agwat.2006.03.014.

Leroux, D.J., Pellarin, T., Vischel, T., Cohard, J.-M., Gascon, T., Gibon, F., Mialon, A., Galle, S., Peugeot, C., Seguis, L., 2016. Assimilation of SMOS soil moisture into a distributed hydrological model and impacts on the water cycle variables over the Ouémé catchment in Benin. Hydrol. Earth Syst. Sci. 20, 2827-2840. http://dx.doi. org/10.5194/hess-20-2827-2016.

Lin, T., Cheng, F., 2016. Impact of soil moisture initialization and soil texture on simulated land-atmosphere interaction in Taiwan. J. Hydrometeor. 17, 1337-1355. http://dx.doi.org/10.1175/JHM-D-15-0024.1.

Lu, L., Shuttleworth, W.J., 2002. Incorporating NDVI-derived LAI into the climate version of RAMS and its impact on regional climate. J. Hydrometeor. 3, 347-362. http://dx. doi.org/10.1175/1525-7541(2002)003<0347:INDLIT > 2.0.CO;2.

Mahrer, Y., Pielke, R.A., 1977. A numerical study of the airflow over irregular terrain. Contrib. Atmos. Phys. 50, 98-113.

McCumber, M.C., Pielke, R.A., 1981. Simulation of the effects of surface fluxes of heat and moisture in a mesoscale numerical model: 1. Soil layer. J. Geophys. Res. 86 (C10), 9929-9938. http://dx.doi.org/10.1029/JC086iC10p09929.

Meng, L., Shen, Y., 2014. On the relationship of soil moisture and extreme temperatures in east China. Earth Interact. 18, 1-20. http://dx.doi.org/10.1175/2013EI000551.1.

NCEP (National Centers for Environmental Prediction), National Weather Service, NOAA, U.S. Department of Commerce, 2015. NCEP FNL Operational Model Global Tropospheric Analyses, Continuing from July 1999. Research Data Archive at the National Center for Atmospheric Research. Computational and Information Systems Laboratory. 2000. Available online: http://www.rda.ucar.edu/datasets/ds083.2 (Accessed on 27 March 2015).

Pathirana, A., Denekew, H.B., Veerbeek, W., Zevenbergen, C., Banda, A.T., 2014. Impact of urban growth-driven landuse change on microclimate and extreme precipitation a sensitivity study. Atmos. Res. 138, 59-72. http://dx.doi.org/10.1016/j.atmosres. 2013.10.005.

Peel, M.C., Finlayson, B.L., McMahon, T.A., 2007. Updated world map of the KöppenGeiger climate classification. Hydrol. Earth Syst. Sci. 11 (5), 1633-1644. http://dx. doi.org/10.5194/hess-11-1633-2007.

Pielke Sr., R.A., 2013. Mesoscale Meteorological Modeling, 3rd edition. Academic Press, San Diego, CA 760 pp.

Rodell, M., Houser, P.R., Jambor, U., Gottschalck, J., Mitchell, K., Meng, C.J., Arsenault, 
K., Cosgrove, B., Radakovich, J., Bosilovich, M., Entin, J.K., Walker, J.P., Lohmann, D., Toll, D., 2004. The global land data assimilation system. Bull. Am. Meteorol. Soc. 85, 381-394. http://dx.doi.org/10.1175/BAMS-85-3-381.

Sánchez, J.M., Kustas, W.P., Caselles, V., Anderson, M., 2008. Modelling surface energy fluxes over maize using a two-source patch model and radiometric soil and canopy temperature observations. Remote Sens. Environ. 112, 1130-1143. http://dx.doi. org/10.1016/j.rse.2007.07.018.

Sánchez, J.M., Caselles, V., Niclòs, R., Coll, C., Kustas, W.P., 2009. Estimating energy balance fluxes above a boreal forest from radiometric temperature observations. Agric. For. Meteorol. 149, 1037-1049. http://dx.doi.org/10.1016/j.agrformet.2008. 12.009.

Sánchez, J.M., López-Urrea, R., Rubio, E., Caselles, V., 2011. Determining water use of sorghum from two-source energy balance and radiometric temperatures. Hydrol. Earth Syst. Sci. 15, 3061-3070. http://dx doi.org/10.5194/hess-15-3061-2011.

Sánchez, J.M., López-Urrea, R., Rubio, E., González-Piqueras, J., Caselles, V., 2014. Assessing crop coefficients of sunflower and canola using two-source energy balance and thermal radiometry. Agric. Water Manag. 137, 23-29. http://dx.doi.org/10. 1016/j.agwat.2014.02.002.

Sánchez, J.M., Bisquert, M., Rubio, E., Caselles, V., 2015a. Impact of land cover change induced by a fire event on the surface energy fluxes derived from remote sensing. Remote Sens. 7, 14899-14915. http://dx.doi.org/10.3390/rs71114899.

Sánchez, J.M., López-Urrea, R., Doña, C., Caselles, V., González-Piqueras, J., Niclòs, R., 2015b. Modeling evapotranspiration in a spring wheat from thermal radiometry:crop coefficients and E/T partitioning. Irrig. Sci. 33, 399-410. http://dx.doi.org/10.1007/ s00271-015-0476-2.

Santanello Jr., J.A., Peters-Lidard, C.D., Kennedy, A., Kumar, S.V., 2013. Diagnosing the nature of land-atmosphere coupling: a case study of dry/wet extremes in the U. S. southern great plains. J. Hydrometeorol. 14, 3-24. http://dx.doi.org/10.1175/JHMD-12-023.1.

Seneviratne, S.I., Corti, T., Davin, E.L., Hirschi, M., Jaeger, E.B., Lehner, I., Orlowsky, B., Teuling, A.J., 2010. Investigating soil moisture-climate interactions in a changing climate: a review. Earth Sci. Rev. 99, 125-161. http://dx.doi.org/10.1016/j. earscirev.2010.02.004.

Steeneveld, G.J., Tolk, L.F., Moene, A.F., Hartogensis, O.K., Peters, W., Holtslag, A.A.M., 2011. Confronting the WRF and RAMS mesoscale models with innovative observations in the Netherlands: evaluating the boundary layer heat budget. J. Geophys. Res. Atmos. D23, D23114.

Tremback, C.J., Kessler, R., 1985. A surface temperature and moisture parameterization for use in mesoscale models. Preprints, Seventh Conf. on Numerical Weather Prediction, Montreal, PQ, Canada. Am. Meteor. Soc. 355-358.

Walko, R.L., Band, L.E., Baron, J., Kittel, T.G.F., Lammers, R., Lee, T.J., Ojima, D., Pielke, R.A., Taylor, C., Tague, C., Tremback, C.J., Vidale, P.L., 2000. Coupled atmosphericbiophysics-hydrology models for environmental modeling. J. Appl. Meteorol. 39, 931-944. http://dx.doi.org/10.1175/1520-0450(2000)039<0931:CABHMF $>2.0$. $\mathrm{CO} ; 2$.

Zaitchik, B.F., Santanello, J.A., Kumar, S.V., Peters-Lidard, C.D., 2013. Representation of soil moisture feedbacks during drought in NASA unified WRF (NU-WRF). J. Hydrometeorol. 14, 360-367. http://dx.doi.org/10.1175/JHM-D-12-069.1. 